Author affiliations and support information (if applicable) appear at the end of this article.

Published at jco.org on May 30, 2018

A.C.W. and M.E.H.H. were Expert Panel Co-Chairs. K.H.A., L.M.M., and M.D. were Expert Panel Steering Committee members

Clinical Practice Guideline Committee approved: October 2, 2017.

Editor's note: This American Society of Clinical Oncology Clinical Practice

Guideline provides recommendations, with comprehensive review and analyses of the relevant literature for each recommendation. Additional information, including a Data Supplement with additional evidence tables, a Methodology Supplement, slide sets, clinical tools and resources, and links to patient information at www.cancer.net, is available at www asco.org/breast-cancer-guidelines.

Reprint Requests: 2318 Mill Road, Suite 800, Alexandria, VA 22314; guidelines@ asco.org

Authors' disclosures of potential conflicts of interest and author contributions are found at the end of this article.

Corresponding author: American Society of Clinical Oncology, 2318 Mill Rd, Suite 800, Alexandria, VA 22314; e-mail:

guidelines@asco.org.

(c) 2018 by American Society of Clinical Oncology and College of American Pathologists

0732-183X/18/3620w-2105w/\$20.00

\section{ASSOCIATED CONTENT}

Q Appendix DOI: https://doi.org/10.1200/JCO 2018.77.8738

(2) Data Supplement DOI: https://doi.org/10.1200/JCO 2018.77.8738

DOI: https://doi.org/10.1200/JCO.2018 77.8738

\title{
Human Epidermal Growth Factor Receptor 2 Testing in Breast Cancer: American Society of Clinical Oncology/ College of American Pathologists Clinical Practice Guideline Focused Update
}

Antonio C. Wolff, M. Elizabeth Hale Hammond, Kimberly H. Allison, Brittany E. Harvey, Pamela B. Mangu, John M.S. Bartlett, Michael Bilous, Ian O. Ellis, Patrick Fitzgibbons, Wedad Hanna, Robert B. Jenkins, Michael F. Press, Patricia A. Spears, Gail H. Vance, Giuseppe Viale, Lisa M. McShane, and Mitchell Dowsett

\section{$\begin{array}{llllllll}\text { A } & \text { B } & \text { S } & \text { T } & \text { R } & \text { A } & \text { C } & \text { T }\end{array}$}

\section{Purpose}

To update key recommendations of the American Society of Clinical Oncology/College of American Pathologists human epidermal growth factor receptor 2 (HER2) testing in breast cancer guideline.

\section{Methods}

Based on the signals approach, an Expert Panel reviewed published literature and research survey results on the observed frequency of less common in situ hybridization (ISH) patterns to update the recommendations.

\section{Recommendations}

Two recommendations addressed via correspondence in 2015 are included. First, immunohistochemistry $(\mathrm{IHC}) 2+$ is defined as invasive breast cancer with weak to moderate complete membrane staining observed in $>10 \%$ of tumor cells. Second, if the initial HER2 test result in a core needle biopsy specimen of a primary breast cancer is negative, a new HER2 test may (not "must") be ordered on the excision specimen based on specific clinical criteria. The HER2 testing algorithm for breast cancer is updated to address the recommended work-up for less common clinical scenarios (approximately $5 \%$ of cases) observed when using a dual-probe ISH assay. These scenarios are described as ISH group 2 (HER2/chromosome enumeration probe 17 [CEP17] ratio $\geq 2.0$; average HER2 copy number < 4.0 signals per cell), ISH group 3 (HER2/CEP17 ratio < 2.0; average HER2 copy number $\geq 6.0$ signals per cell), and ISH group 4 (HER2/CEP17 ratio < 2.0; average HER2 copy number $\geq 4.0$ and $<6.0$ signals per cell). The diagnostic approach includes more rigorous interpretation criteria for ISH and requires concomitant IHC review for dual-probe ISH groups 2 to 4 to arrive at the most accurate HER2 status designation (positive or negative) based on combined interpretation of the ISH and IHC assays. The Expert Panel recommends that laboratories using single-probe ISH assays include concomitant IHC review as part of the interpretation of all singleprobe ISH assay results.

Find additional information at www.asco.org/breast-cancer-guidelines.

J Clin Oncol 36:2105-2122. (C) 2018 by American Society of Clinical Oncology and College of American Pathologists

\section{INTRODUCTION}

First released in 2007 and updated in 2013, the recommendations by the American Society of Clinical Oncology (ASCO)/College of American Pathologists (CAP) human epidermal growth factor receptor 2 (HER2) testing Expert Panel are aimed at improving the analytic validity of HER2 testing and the clinical utility of HER2 as a predictive biomarker for potential responsiveness to therapies targeting the HER2 protein. ${ }^{1-4}$ Activating mutations of the tyrosine kinase and extracellular domains of HER2 in the absence of amplification or overexpression offer an alternative and much less common mechanism for HER2-targeted therapy that is being explored in clinical trials of small molecule kinase inhibitors. ${ }^{5}$ Data from 


\section{Human Epidermal Growth Factor Receptor 2 Testing in Breast Cancer: American Society of Clinical Oncology/ College of American Pathologists Clinical Practice Guideline Focused Update}

\section{Guideline Questions}

What is the most appropriate definition for immunohistochemistry (IHC) 2+ (IHC equivocal)? Must human epidermal growth factor receptor 2 (HER2) testing be repeated on a surgical specimen if initially negative test on core biopsy? What is the optimal algorithm for less common patterns observed when performing dual-probe in situ hybridization (ISH) testing in breast cancer?

\section{Target Population}

Patients with breast cancer.

\section{Target Audience}

Medical oncologists, pathologists, surgeons, and radiation oncologists.

\section{Methods}

An Expert Panel was convened to develop updated clinical practice guideline recommendations based on a systematic review of the medical literature.

\section{Focused Update Recommendations}

1. In the revised Figure 1, the revised definition of IHC 2+ (equivocal) is invasive breast cancer with "weak to moderate complete membrane staining observed in $>10 \%$ of tumor cells."

2. In the revised Table 2, it is now stated that, on the basis of some criteria (including a tumor grade 3), "If the initial HER2 test result in a core needle biopsy specimen of a primary breast cancer is negative, a new HER 2 test may be ordered on the excision specimen ..."

3. If a case has a HER2/chromosome enumeration probe 17 (CEP17) ratio of $\geq 2.0$ but the average HER2 signals per cell is $<4.0$, a definitive diagnosis will be rendered based on additional work-up. If not already assessed by the institution or laboratory performing the ISH test, IHC testing for HER2 should be performed using sections from the same tissue sample used for ISH and the slides from both ISH and IHC should be reviewed together to guide the selection of areas to score by ISH (local practice considerations will dictate the best procedure to accomplish this concomitant review):

a. If the IHC result is $3+$, diagnosis is HER2 positive.

b. If the IHC result is $2+$, recount ISH by having an additional observer, blinded to previous ISH results, count at least 20 cells that include the area of invasive cancer with IHC 2+ staining:

- If reviewing the count by the additional observer changes the result into another ISH category, the result should be adjudicated per internal procedures to define the final category.

- If the count remains an average of $<4.0$ HER2 signals per cell and the HER2/CEP17 ratio is $\geq 2.0$, diagnosis is HER2 negative with a comment. (Please note: Refer to text for specific comments about recommendations listed as $3 \mathrm{~b}, 3 \mathrm{c}, 4 \mathrm{c}, 5 \mathrm{~b}$, and $5 \mathrm{c}$ ).

c. If the IHC result is 0 or $1+$, diagnosis is HER2 negative with a comment. (Please note: Refer to text for specific comments about recommendations listed as $3 b, 3 c, 4 c$, 5b, and $5 c$ ).

4. If a case has an average of $\geq 6.0$ HER2 signals per cell with a HER2/CEP17 ratio of $<2.0$, formerly diagnosed as ISH positive for HER2, a definitive diagnosis will be rendered based on additional work-up. If not already assessed by the institution or laboratory performing the ISH test, IHC testing for HER2 should be performed using sections from the same tissue sample used for ISH and the slides from both ISH and IHC should be reviewed together to guide the selection of areas to score by ISH (local practice considerations will dictate the best procedure to accomplish this concomitant review):

a. If the IHC result is $3+$, diagnosis is HER2 positive.

b. If the IHC result is $2+$, recount ISH by having an additional observer, blinded to previous ISH results, count at least 20 cells that include the area of invasion with IHC 2+ staining:

(continued on following page) 


\section{THE BOTTOM LINE (CONTINUED)}

- If reviewing the count by the additional observer changes the result into another ISH category, the result should be adjudicated per internal procedures to define the final category.

- If the HER2/CEP17 ratio remains $<2.0$ with $\geq 6.0$ HER2 signals per cell, diagnosis is HER2 positive.

c. If the IHC result is 0 or $1+$, diagnosis is HER2 negative with a comment. (Please note: Refer to text for specific comments about recommendations listed as $3 b, 3 c, 4 c$, 5b, and $5 c$ ).

5. If the case has an average HER2 signals per tumor cell of $\geq 4.0$ and $<6.0$ and the HER2/CEP17 ratio is $<2.0$, formerly diagnosed as ISH equivocal for HER2, a definitive diagnosis will be rendered based on additional work-up. If not already assessed by the institution or laboratory performing the ISH test, IHC testing for HER2 should be performed using sections from the same tissue sample used for ISH and the slides from both ISH and IHC should be reviewed together to guide the selection of areas to score by ISH (local practice considerations will dictate the best procedure to accomplish this concomitant review):

a. If the IHC result is $3+$, diagnosis is HER2 positive.

b. If the IHC result is $2+$, recount ISH by having an additional observer, blinded to previous ISH results, count at least 20 cells that include the area of invasion with IHC $2+$ staining:

- If reviewing the count by the additional observer changes the result into another ISH category, the result should be adjudicated per internal procedures to define the final category.

- If the count remains an average of $\geq 4.0$ and $<6.0$ HER2 signals per cell with a HER2/CEP17 ratio of $<2.0$, diagnosis is HER2 negative with a comment. (Please note: Refer to text for specific comments about recommendations listed as $3 \mathrm{~b}, 3 \mathrm{c}, 4 \mathrm{c}, 5 \mathrm{~b}$, and $5 \mathrm{c}$ ).

c. If the IHC result is 0 or $1+$, diagnosis is HER2 negative with a comment. (Please note: Refer to text for specific comments about recommendations listed as $3 b, 3 c, 4 c$, 5b, and $5 c$ ).

Note: In Figure 2, a new footnote states that the Expert Panel recommends that concomitant IHC review become part of the interpretation of single-probe ISH results and that the Expert Panel preferentially recommends the use of dual-probe instead of singleprobe ISH assays.

Refer to Table 1 for the full list of recommendations.

\section{Additional Resources}

More information, including a Data Supplement with additional evidence tables, a Methodology Supplement with information about evidence quality and strength of recommendations, slide sets, and clinical tools and resources, is available at www.asco.org/breastcancer-guidelines. Patient information is available at www.cancer.net

ASCO believes that cancer clinical trials are vital to inform medical decisions and improve cancer care, and that all patients should have the opportunity to participate.

NRG trial B-47 (ClinicalTrials.gov identifier: NCT01275677) confirmed the lack of benefit from adjuvant trastuzumab for patients whose tumors lack gene amplification and are immunohistochemistry (IHC) $1+$ or $2+{ }^{6}$ Consequently, HER2 gene amplification assessed by in situ hybridization (ISH) or protein overexpression assessed by IHC remains the primary predictor of responsiveness to HER2-targeted therapies in breast cancer.

Greater communication among health care providers (especially pathologists and oncologists) and appropriate infrastructure support for specimen handling and laboratory facilities led to observed improvements in the analytic performance and accuracy of HER2 testing. ${ }^{7}$ Greater clinical experience with the efficacy and safety of HER2-targeted therapies, and a meaningful reduction in the high frequency of false-positive HER2 test results previously observed, ${ }^{8}$ led the 2013 Expert Panel to provide additional guidance regarding less common clinical scenarios to allow greater discrimination between positive and negative results. ${ }^{1,4}$

Since 2013, several laboratory and clinical investigators have reported on the practical implications of the 2013 Guideline Update and the observed frequency of equivocal cases. ${ }^{9-13}$ These reports have allowed the Expert Panel to evaluate the observed frequency of less common HER2 testing patterns, their apparent prognostic and predictive value when retrospectively analyzed within clinical trial data sets, and the critical need to understand the underlying distribution of HER2 IHC test results in cases that are submitted for additional testing (eg, by ISH) by a reference laboratory. The Expert Panel wished to clarify one of its 2013 recommendations that led some laboratories to adopt the use of 
Table 1. Summary of All Recommendations (original recommendations and focused update recommendations)

\begin{tabular}{|c|c|}
\hline Topic & 2013 Recommendations \\
\hline Specimens to be tested & $\begin{array}{l}\text { All newly diagnosed patients with breast cancer must have } \\
\text { a HER2 test performed. Patients who then develop } \\
\text { metastatic disease must have a HER2 test performed in } \\
\text { a metastatic site, if tissue sample is available. }\end{array}$ \\
\hline $\begin{array}{l}\text { Optimal algorithm for } \\
\text { HER2 testing }\end{array}$ & 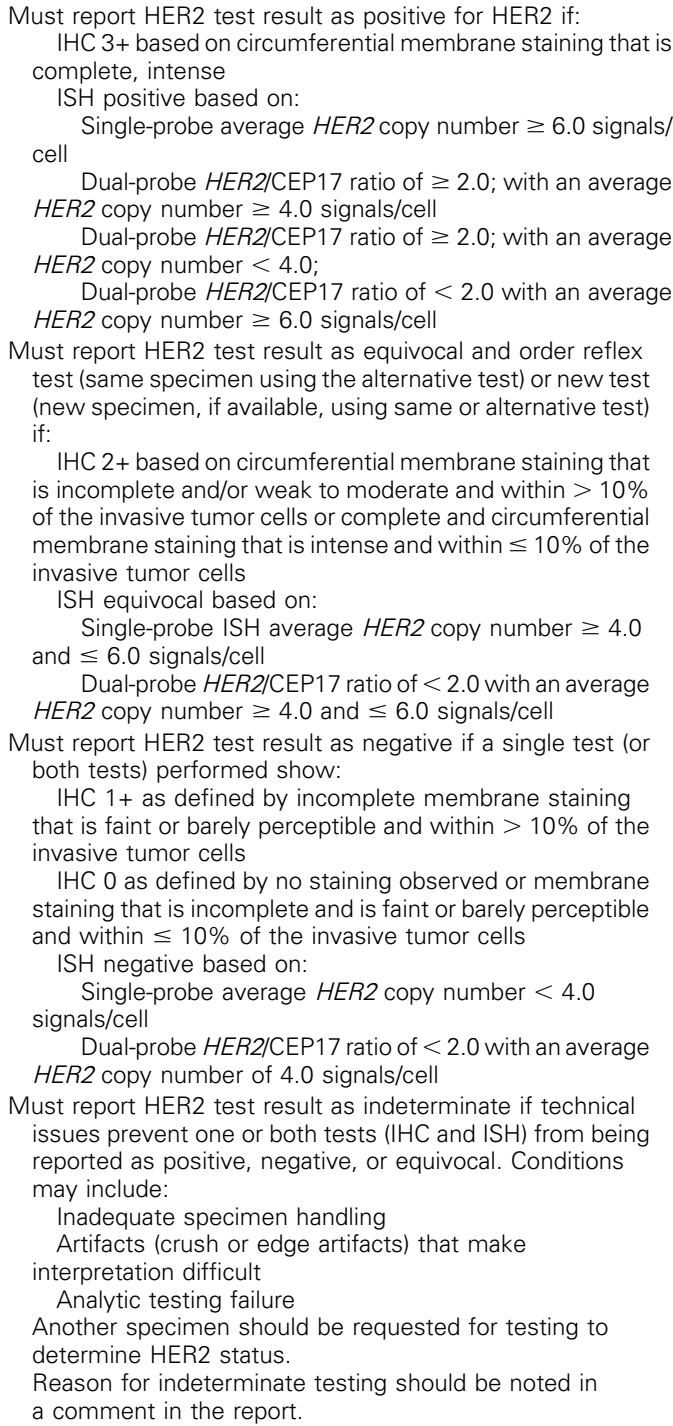 \\
\hline
\end{tabular}

(continued on following page)

No change.

1. In the revised Figure 1, the revised definition of $\mathrm{IHC} 2+$ (equivocal) is invasive breast cancer with "weak to moderate complete membrane staining observed in $>10 \%$ of tumor cells."

2. In the revised Table 2, it is now stated that, on the basis of some criteria (including a tumor grade 3), "If the initial HER2 test result in a core needle biopsy specimen of a primary breast cancer is negative, a new HER2 test may be ordered on the excision specimen ..."

3. If a case has a HER2/CEP17 ratio of $\geq 2.0$ but the average HER2 signals/cell is $<4.0$, a definitive diagnosis will be rendered based on additional work-up. If not already assessed by the institution or laboratory performing the ISH test, IHC testing for HER2 should be performed using sections from the same tissue sample used for ISH, and the slides from both ISH and IHC should be reviewed together to guide the selection of areas to score by ISH (local practice considerations will dictate the best procedure to accomplish this concomitant assessment):

a. If the IHC result is $3+$, diagnosis is HER2 positive

b. If the IHC result is $2+$, recount ISH by having an additional observer, blinded to previous ISH results, count at least 20 cells that include the area of invasive cancer with $\mathrm{IHC}$ $2+$ staining:

If reviewing the count by the additional observer changes the result into another ISH category, the result should be adjudicated per internal procedures to define the final category.

If the count remains an average of $<4.0 \mathrm{HER} 2$ signals cell and the HER2/CEP17 ratio is $\geq 2.0$, diagnosis is HER2 negative with a comment*

c. If the $\mathrm{IHC}$ result is 0 or $1+$, diagnosis is HER2 negative with a comment.*

4. If a case has an average of $\geq 6.0 \mathrm{HER} 2$ signals/cell with a HER2/CEP17 ratio of $<2.0$, formerly diagnosed as ISH positive for HER2, a definitive diagnosis will be rendered based on additional work-up. If not already assessed by the institution or laboratory performing the ISH test, IHC testing for HER2 should be performed using sections from the same tissue sample used for ISH, and the slides from both ISH and $\mathrm{IHC}$ should be reviewed together to guide the selection of areas to score by ISH (local practice considerations will dictate the best procedure to accomplish this concomitant review):

a. If the $\mathrm{IHC}$ result is $3+$, diagnosis is HER2 positive

b. If the $\mathrm{IHC}$ result is $2+$, recount ISH by having an additional observer, blinded to previous ISH results, count at least 20 cells that include the area of invasion with IHC $2+$ staining:

If reviewing the count by the additional observer changes the result into another ISH category, the result should be adjudicated per internal procedures to define the final category

If the HER2/CEP17 ratio remains $<2.0$ with $\geq 6.0 \mathrm{HER} 2$ signals/cell, diagnosis is HER2 positive

c. If the $\mathrm{IHC}$ result is 0 or $1+$, diagnosis is HER2 negative with a comment*

5. If the case has an average $H E R 2$ signals/tumor cell of $\geq 4.0$ and $<6.0$ and the HER2/CEP17 ratio is $<2.0$, formerly diagnosed as ISH equivocal for HER2, a definitive diagnosis will be rendered based on additional work-up. If not already assessed by the institution or laboratory performing the ISH test, IHC testing for HER2 should be performed using sections from the same tissue sample used for ISH, and the slides from both ISH and IHC should be reviewed together to guide the selection of areas to score by ISH (local practice considerations will dictate the best procedure to accomplish this concomitant review):

a. If the $\mathrm{IHC}$ result is $3+$, diagnosis is HER2 positive

b. If the $\mathrm{IHC}$ result is $2+$, recount ISH by having an additional observer, blinded to previous ISH results, count at least 20 cells that include the area of invasion with $\mathrm{IHC} 2+$ staining: 
Table 1. Summary of All Recommendations (original recommendations and focused update recommendations) (continued)

\begin{tabular}{|c|c|c|}
\hline Topic & 2013 Recommendations & 2018 Focused Update Recommendations \\
\hline & & $\begin{array}{l}\text { If reviewing the count by the additional observer changes } \\
\text { the result into another ISH category, the result should be } \\
\text { adjudicated per internal procedures to define the final category } \\
\text { If the count remains an average of } \geq 4.0 \text { and }<6.0 \mathrm{HER} 2 \\
\text { signals/cell with a HER2/CEP17 ratio of }<2.0 \text {, diagnosis is } \\
\text { HER2 negative with a comment* } \\
\text { C. If the IHC result is } 0 \text { or } 1+\text {, diagnosis is HER2 negative } \\
\text { with a comment* }\end{array}$ \\
\hline ISH rejection criteria & $\begin{array}{l}\text { Test is rejected and repeated if: } \\
\text { Controls are not as expected } \\
\text { Observer cannot find and count at least two areas of } \\
\text { invasive tumor } \\
>25 \% \text { of signals are unscorable due to weak signals } \\
>10 \% \text { of signals occur over cytoplasm } \\
\text { Nuclear resolution is poor } \\
\text { Autofluorescence is strong } \\
\text { Report HER2 test result as Indeterminate as per } \\
\text { parameters described. }\end{array}$ & No change \\
\hline ISH interpretation & $\begin{array}{l}\text { The pathologist should scan the entire ISH slide before counting } \\
\text { at least } 20 \text { cells or use IHC to define the areas of potential } \\
\text { HER2 amplification. } \\
\text { If there is a second population of cells with increased HER2 } \\
\text { signals/cell and this cell population consists of }>10 \% \text { of } \\
\text { tumor cells on the slide (defined by image analysis or visual } \\
\text { estimation of the ISH or IHC slide), a separate counting of at } \\
\text { least } 20 \text { nonoverlapping cells must also be performed within } \\
\text { this cell population and reported. } \\
\text { For brightfield ISH, counting requires comparison between } \\
\text { patterns in normal breast and tumor cells because artifactual } \\
\text { patterns may be seen that are difficult to interpret. If tumor } \\
\text { cell pattern is neither normal nor clearly amplified, test should } \\
\text { be submitted for expert opinion. }\end{array}$ & $\begin{array}{l}\text { The pathologist should scan the entire ISH slide before counting } \\
\text { at least } 20 \text { cells or use IHC to define the areas of potential } \\
H E R 2 \text { amplification. } \\
\text { If there is a second population of contiguous cells with } \\
\text { increased HER2 signals/cell and this cell population consists } \\
\text { of }>10 \% \text { of tumor cells on the slide (defined by image } \\
\text { analysis or visual estimation of the ISH or IHC slide), } \\
\text { a separate counting of at least } 20 \text { nonoverlapping cells must } \\
\text { also be performed within this cell population and reported. }\end{array}$ \\
\hline $\begin{array}{l}\text { Acceptable (IHC and } \\
\text { ISH) tests }\end{array}$ & $\begin{array}{l}\text { Should preferentially use an FDA-approved IHC, brightfield ISH, } \\
\text { or FISH assay. }\end{array}$ & No change \\
\hline $\mathrm{IHC}$ rejection criteria & $\begin{array}{l}\text { Test is rejected and repeated or tested by FISH if: } \\
\text { Controls are not as expected } \\
\text { Artifacts involve most of sample } \\
\text { Sample has strong membrane staining of normal breast } \\
\text { ducts (internal controls) }\end{array}$ & No change \\
\hline $\begin{array}{l}\text { IHC interpretation } \\
\text { criteria }\end{array}$ & $\begin{array}{l}\text { Should interpret IHC test using a threshold of }>10 \% \text { of tumor } \\
\text { cells that must show homogeneous, dark circumferential } \\
\text { (chicken wire) pattern to call result } 3+, \text { HER2 positive. }\end{array}$ & No change \\
\hline $\begin{array}{l}\text { Reporting } \\
\text { requirements for all } \\
\text { assay types }\end{array}$ & $\begin{array}{l}\text { Report must include guideline-detailed elements except for } \\
\text { changes to reporting requirement and algorithms defined in } \\
\text { this table. }\end{array}$ & No change \\
\hline $\begin{array}{l}\text { Optimal tissue handling } \\
\text { requirements }\end{array}$ & $\begin{array}{l}\text { Time from tissue acquisition to fixation should be as short as } \\
\text { possible; samples for HER2 testing are fixed in } 10 \% \text { neutral } \\
\text { buffered formalin for } 6-72 \text { hours; cytology specimens must } \\
\text { be fixed in formalin. } \\
\text { Samples should be sliced at } 5 \text { - to } 10-\mathrm{mm} \text { intervals after } \\
\text { appropriate gross inspection and margin designation and } \\
\text { placed in a sufficient volume of neutral buffered formalin. } \\
\text { Any exceptions to this process must be included in the report. }\end{array}$ & No change \\
\hline $\begin{array}{l}\text { Optimal tissue } \\
\text { sectioning } \\
\text { requirements }\end{array}$ & $\begin{array}{l}\text { Sections should ideally not be used for HER2 testing if cut }>6 \\
\text { weeks earlier; this may vary with primary fixation or storage } \\
\text { conditions }\end{array}$ & No change \\
\hline $\begin{array}{l}\text { Optimal internal } \\
\text { validation procedure }\end{array}$ & Validation of test must be performed before test is offered & No change \\
\hline $\begin{array}{l}\text { Optimal initial test } \\
\text { validation }\end{array}$ & $\begin{array}{l}\text { Laboratories performing these tests should be following all } \\
\text { accreditation requirements, one of which is initial testing } \\
\text { validation. The laboratory should ensure that initial validation } \\
\text { conforms to the published } 2010 \text { ASCO/CAP } \\
\text { recommendations for IHC testing of ER and PgR guideline } \\
\text { validation requirements with } 20 \text { negative and } 20 \text { positive for } \\
\text { FDA-approved assays and } 40 \text { negative and } 40 \text { positive for } \\
\text { LDTs. This requirement does not apply to assays that were } \\
\text { previously validated in conformance with the } 2007 \text { ASCO/ } \\
\text { CAP HER2 testing guideline, and those who routinely } \\
\text { participate in external proficiency testing for HER2 tests, } \\
\text { such as the program offered by CAP. } \\
\text { (continued on following page) }\end{array}$ & No change \\
\hline
\end{tabular}




\begin{tabular}{|c|c|c|}
\hline Topic & 2013 Recommendations & 2018 Focused Update Recommendations \\
\hline $\begin{array}{l}\text { Optimal initial test } \\
\text { validation }\end{array}$ & $\begin{array}{l}\text { Laboratories are responsible for ensuring the reliability and } \\
\text { accuracy of their testing results, by compliance with } \\
\text { accreditation and proficiency testing requirements for HER2 } \\
\text { testing assays. Specific concordance requirements are not } \\
\text { required. }\end{array}$ & No change \\
\hline $\begin{array}{l}\text { Optimal monitoring of } \\
\text { test concordance } \\
\text { between methods }\end{array}$ & See text following under Optimal Laboratory Accreditation & No change \\
\hline $\begin{array}{l}\text { Optimal internal QA } \\
\text { procedures }\end{array}$ & $\begin{array}{l}\text { Should review and document external and internal controls with } \\
\text { each test and each batch of tests. } \\
\text { Ongoing quality control and equipment maintenance } \\
\text { Initial and ongoing laboratory personnel training and } \\
\text { competency assessment } \\
\text { Use of standardized operating procedures including routine } \\
\text { use of control materials } \\
\text { Revalidation of procedure if changed } \\
\text { Ongoing competency assessment and documentation of } \\
\text { the actions taken as a part of the laboratory record. }\end{array}$ & No change \\
\hline $\begin{array}{l}\text { Optimal external } \\
\text { proficiency } \\
\text { assessment }\end{array}$ & $\begin{array}{l}\text { Participation in and successful completion of external } \\
\text { proficiency testing program with at least two testing events } \\
\text { (mailings) a year } \\
\text { Satisfactory performance requires at least } 90 \% \text { correct } \\
\text { responses on graded challenges for either test } \\
\text { Unsatisfactory performance will require laboratory to } \\
\text { respond according to accreditation agency program } \\
\text { requirements }\end{array}$ & No change \\
\hline $\begin{array}{l}\text { Optimal laboratory } \\
\text { accreditation }\end{array}$ & $\begin{array}{l}\text { Onsite inspection every other year with annual requirement for } \\
\text { self-inspection } \\
\text { Reviews laboratory validation, procedures, QA results and } \\
\text { processes, results, and reports } \\
\text { Unsatisfactory performance results in suspension of } \\
\text { laboratory testing for HER2 for that method }\end{array}$ & No change \\
\hline
\end{tabular}

multiple alternative chromosome 17 probe testing as the sole strategy to resolve equivocal HER2 test results by ISH, despite limited evidence on analytical and clinical validity. The full set of recommendations from 2013 and 2018, highlighting changes, is available in Table 1.

The HER2 testing Expert Panel has identified five clinical questions that form the core of this Focused Update. Two of them (Clinical Questions 1 and 2) were addressed in a previous correspondence by the Expert Panel published in Journal of Clinical Oncology (JCO) in $2015^{14}$ and are included here in the form of Figure 1 (algorithm for IHC testing), and Table 2 (histopathologic features suggestive of possible test discordance), both revised from the 2013 guideline. Figure 2 is an algorithm for single-probe ISH testing and includes a new footnote with a recommendation that concomitant IHC review become part of the interpretation of single-probe ISH results. Clinical Questions 3, 4, and 5 address less common patterns observed when performing dualprobe ISH testing $^{10,12}$ and are graphically summarized in Figures 3 to 6 (algorithm for dual-probe ISH testing), also revised.

A new Table 3 describes the patterns of HER2 ISH testing using a dual-probe assay and lists the clear effect of the underlying distribution of HER2 IHC test results on the frequency of less common patterns of ISH (hereafter called groups 2, 3, and 4). ${ }^{10,12}$ In the population at large, approximately $95 \%$ of tumors tested for HER2 by dual-probe ISH will consist of group 1 (HER2 positive) and group 5 (HER2 negative). It is expected that approximately $5 \%$ of cases tested by ISH will fall into groups 2, 3, or 4, and available clinical outcome data from related clinical trials, albeit of limited statistical power, have allowed the Expert Panel to more carefully define the expected prognostic and predictive behavior of these cases.

Most important, after careful consideration of the available evidence and expert opinions, the Expert Panel revised the diagnostic approach to groups 2 to 4 to include more rigorous interpretation criteria for dual-probe ISH testing and to require concomitant IHC review, to arrive at the most accurate HER2 status designation (positive or negative) based on the combined interpretation of the ISH and IHC assays. The Expert Panel recommends that such concomitant review be performed in the same institution to ensure parallel interpretation and quality of the two assays.

While the main focus was to clarify the less common test results observed with the two-probe ISH assays, the recommendations affect the users of single-probe ISH assays. Therefore, the Expert Panel now recommends that concomitant IHC review become part of the interpretation of single-probe ISH results, to allow the most accurate HER2 designation (Fig 2). The Expert Panel also preferentially recommends the use of dual-probe instead of singleprobe ISH assays, while it recognizes that several single-probe ISH assays have regulatory approval in many parts of the world.

\section{GUIDELINE QUESTIONS}

This Focused Update addresses five clinical questions raised after the publication of the 2013 Guideline Update: 


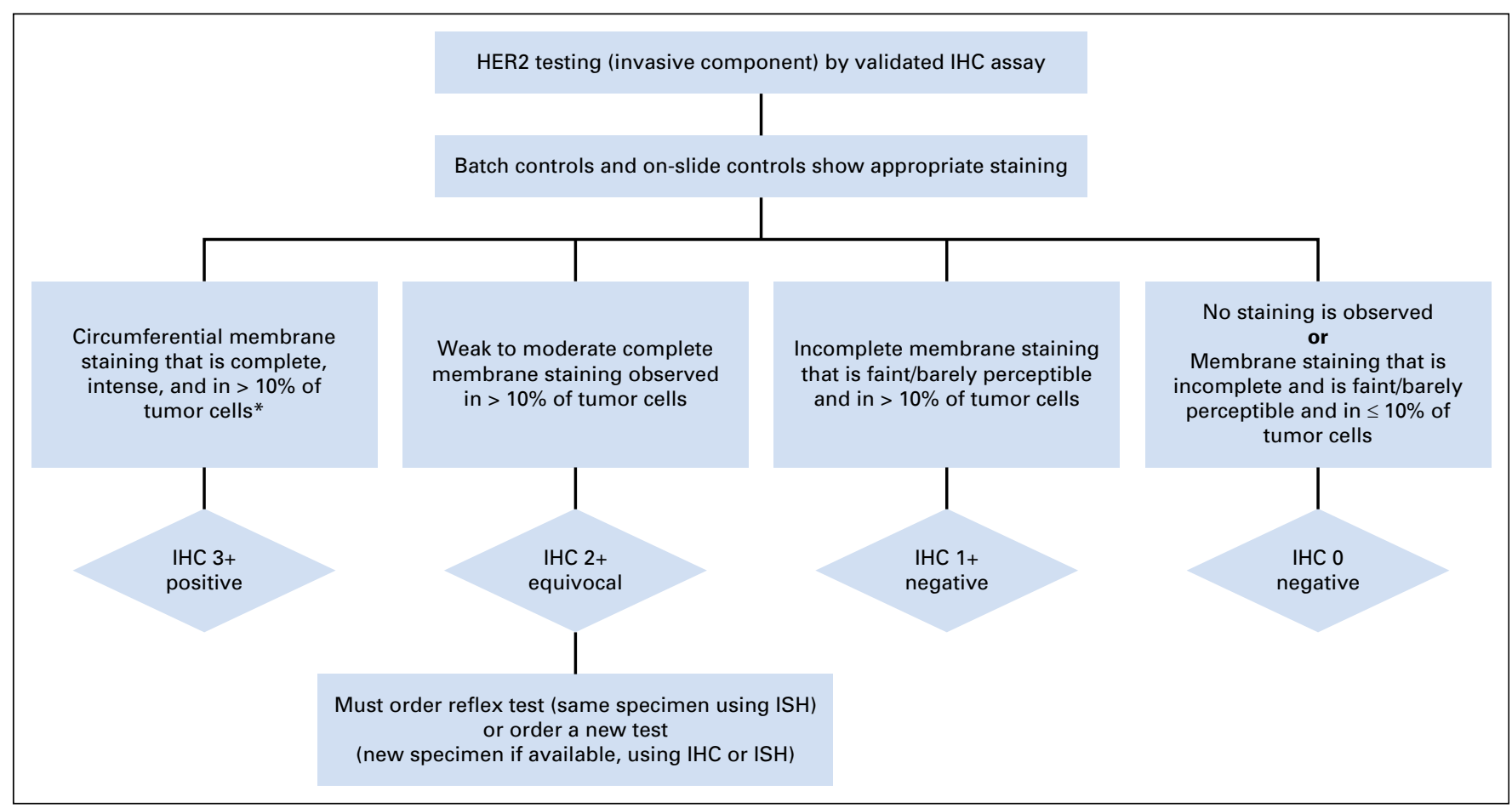

Fig 1. Algorithm for evaluation of human epidermal growth factor receptor 2 (HER2) protein expression by immunohistochemistry (IHC) assay of the invasive component of a breast cancer specimen. Note: The final reported results assume that there is no apparent histopathologic discordance observed by the pathologist. Unusual staining patterns of HER2 by IHC can be encountered that are not covered by these definitions. In practice, these patterns are rare and if encountered should be considered IHC $2+$ equivocal. As one example, some specific subtypes of breast cancers can show IHC staining that is moderate to intense but incomplete (basolateral or lateral) and can be found to be HER2 amplified. Another example is circumferential membrane IHC staining that is intense but in $\leq 10 \%$ of tumor cells (heterogeneous, but limited in extent). Such cases can be considered 2+ equivocal, but additional samples may reveal different percentages of HER2 positive staining. ISH, in situ hybridization. $(*)$ Readily appreciated using a low power objective and observed within a homogeneous and contiguous invasive cell population.

\section{Clinical Question 1}

What is the most appropriate definition for IHC $2+$ (IHC equivocal)?

\section{Clinical Question 2}

Must HER2 testing be repeated on a surgical specimen if initially negative test on core biopsy?

\section{Clinical Question 3}

Should invasive cancers with a HER2/chromosome enumeration probe 17 (CEP17) ratio of $\geq 2.0$ but an average HER2 copy number of $<4.0$ signals per cell be considered ISH positive?

\section{Clinical Question 4}

Should invasive cancers with an average HER2 copy number of $\geq 6.0$ signals per cell but a HER2/CEP17 ratio of $<2.0$ be considered ISH positive?

\section{Clinical Question 5}

What is the appropriate diagnostic work-up for invasive cancers with an average HER 2 copy number of $\geq 4.0$ but $<6.0$ signals per cell and a HER2/CEP17 ratio of $<2.0$ and initially deemed to have an equivocal HER2 ISH test result?

Clinical Questions 1 and 2 were formally addressed in a correspondence from the ASCO/CAP HER2 testing Expert Panel published in $J C O$ in $2015^{14}$ in response to a correspondence by Rakha et $\mathrm{al}^{17}$ and this Focused Update contains a revised Figure 1 (Clinical Question 1) and a revised Table 2 (Clinical Question 2).

Clinical Questions 3, 4, and 5 regarding dual-probe (dualsignal) ISH testing (Figs 3 to 6 ) were addressed by the Expert Panel in a meeting at ASCO headquarters on November 28 and 29, 2016, and in subsequent conference calls and electronic communications. Figure 2 (single-probe ISH) from the 2013 Guideline Update includes a new footnote with a recommendation that concomitant IHC review should become part of the interpretation of singleprobe ISH results. Table 1 contains a summary of the recommendations of the 2013 Guideline Update and the 2018 Focused Update. Figure 7, describing the number of laboratories participating in predictive marker proficiency testing for HER2, has been updated.

\section{METHODS}

\section{Guideline Update Process}

This systematic review-based guideline product was developed by a multidisciplinary Expert Panel (Appendix Table A1, online only), which included a patient representative and ASCO guidelines staff with health research methodology expertise. PubMed and the Cochrane Library were searched for randomized controlled trials, systematic reviews, metaanalyses, and clinical practice guidelines for the period from January 1 , 2013, through May 11, 2017. The disease and intervention search terms 
Table 2. Histopathologic Features Suggestive of Possible HER2 Test Discordance

\section{Criteria to Consider*}

A new HER2 test should not be ordered if the following histopathologic findings occur and the initial HER2 test was negative:

Histologic grade 1 carcinoma of the following types:

Infiltrating ductal or lobular carcinoma, ER and PgR positive

Tubular (at least 90\% pure)

Mucinous (at least $90 \%$ pure)

Cribriform (at least $90 \%$ pure)

Adenoid cystic carcinoma ( $90 \%$ pure) and often triple negative

Similarly, a new HER2 test should be ordered if the following histopathologic findings occur and the initial HER2 test was positive:

Histologic grade 1 carcinoma of the following types:

Infiltrating ductal or lobular carcinoma, ER and PgR positive

Tubular (at least $90 \%$ pure)

Mucinous (at least $90 \%$ pure)

Cribriform (at least $90 \%$ pure)

Adenoid cystic carcinoma ( $90 \%$ pure) and often triple negative

If the initial HER2 test result in a core needle biopsy specimen of a primary breast cancer is negative, a new HER2 test $\boldsymbol{m a y}$ be ordered on the excision specimen if one of the following is observed:

Tumor is grade 3

Amount of invasive tumor in the core biopsy specimen is small

Resection specimen contains high-grade carcinoma that is morphologically distinct from that in the core

Core biopsy result is equivocal for HER2 after testing by both ISH and IHC

There is doubt about the handling of the core biopsy specimen (long ischemic time, short time in fixative, different fixative) or the test is suspected by the pathologist to be negative on the basis of testing error

NOTE. Adapted from 2013 ASCO/CAP HER2 Testing Guideline. ${ }^{1}$

Abbreviations: ER, estrogen receptor; HER2, human epidermal growth factor receptor 2; IHC, immunohistochemistry; ISH, in situ hybridization; PgR, progesterone receptor.

${ }^{*}$ Criteria to consider if there are concerns regarding discordance with apparent histopathologic findings and possible false-negative or false-positive HER2 test result.

were those that were used for the 2013 Guideline Update. The updated search was guided by the signals ${ }^{18}$ approach that is designed to identify only new, potentially practice-changing data (signals) that might translate into revised practice recommendations. The approach relies on targeted routine literature searching and the expertise of ASCO Expert Panel members to help identify potential signals. Additional information about the literature search strategy string and results, as well as a discussion of the ASCO signals approach to guideline

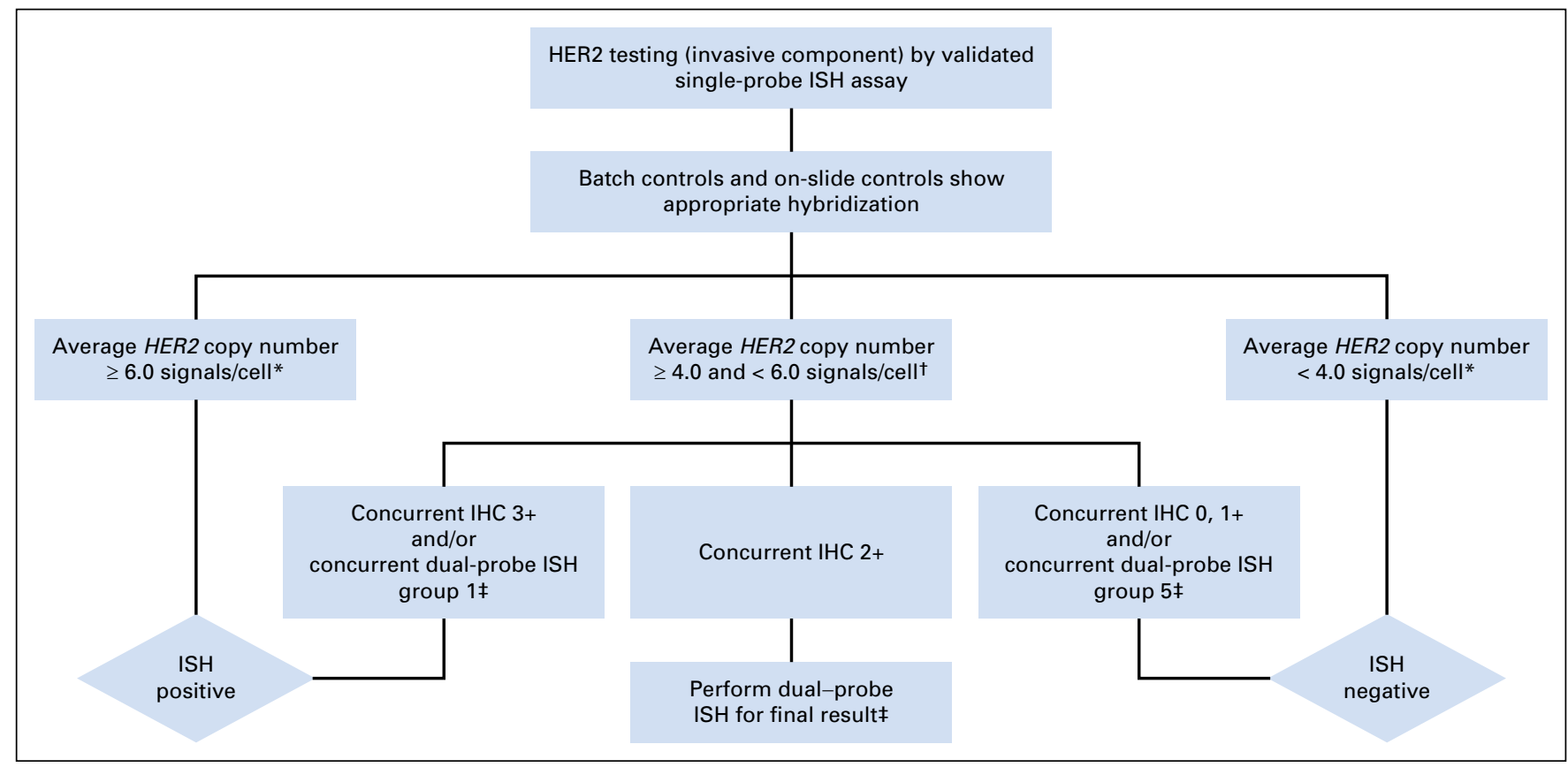

Fig 2. Algorithm for evaluation of human epidermal growth factor receptor 2 (HER2) gene amplification by in situ hybridization (ISH) assay of the invasive component of

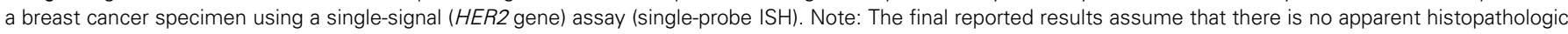

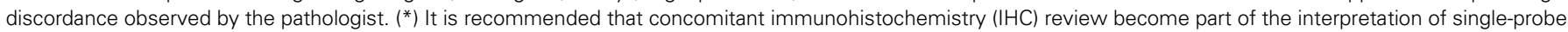

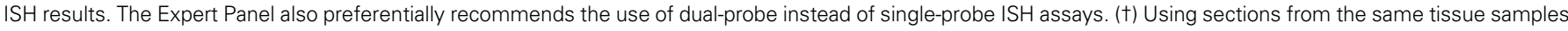

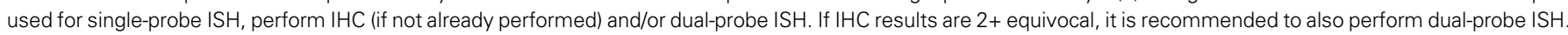
( $¥)$ If initial assessment of dual-probe ISH is suggestive of groups 2,3 , or 4, follow the algorithm described in Figure 3. 


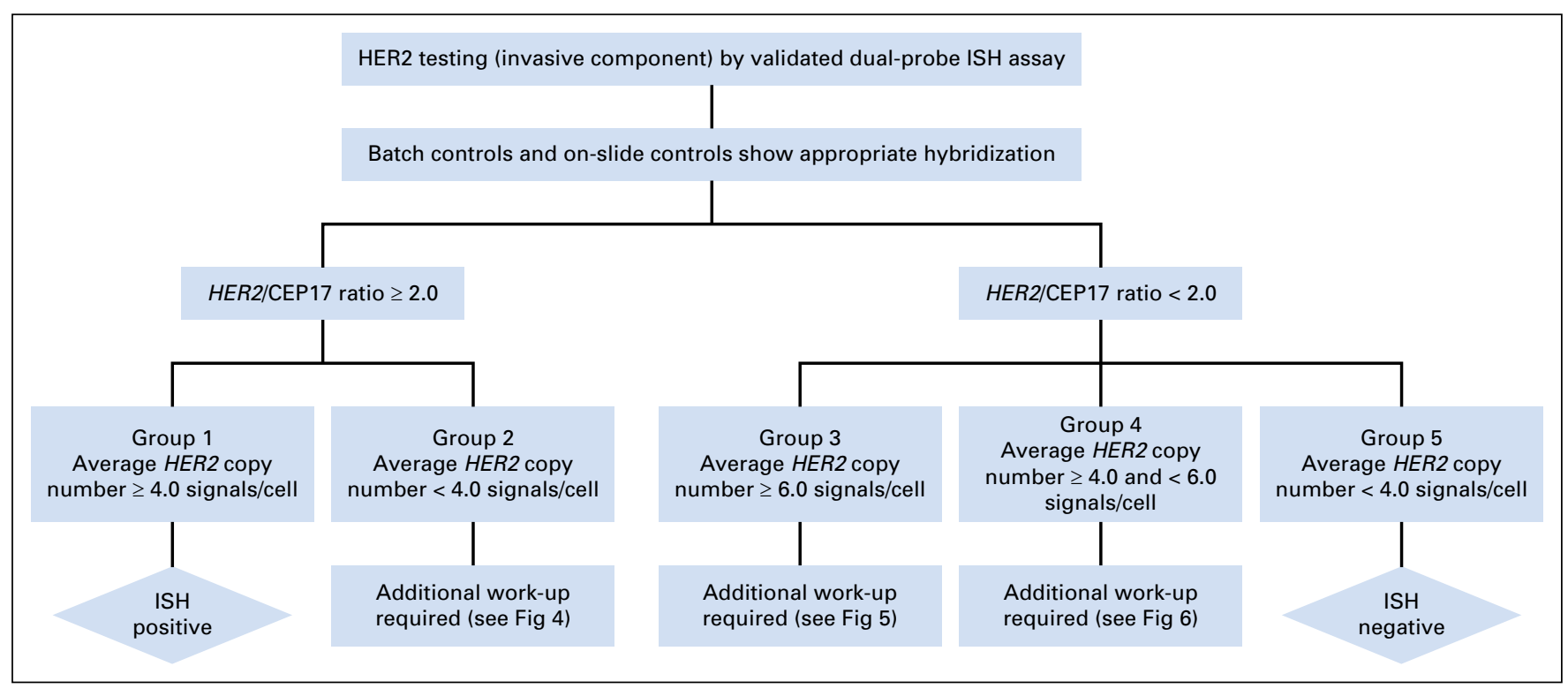

Fig 3. Algorithm for evaluation of human epidermal growth factor receptor 2 (HER2) gene amplification by in situ hybridization (ISH) assay of the invasive component of

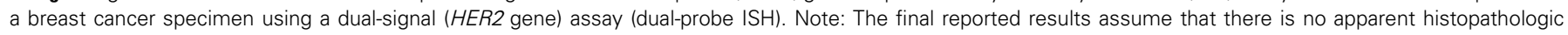

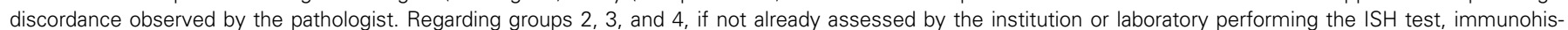

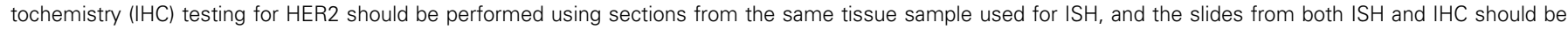

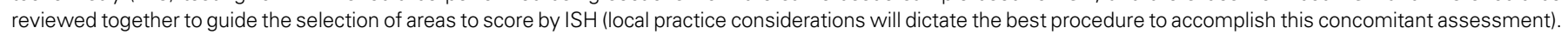
CEP17, chromosome enumeration probe 17.

updating, are available at www.asco.org/breast-cancer-guidelines and in the 2018 Data Supplement and 2018 Methodology Supplement, respectively. A QUOROM diagram of the updated search and the clinical questions are provided (Data Supplement). In addition to the literature search, a research survey was distributed to gather additional realworld data from laboratories from before and after implementation of the ASCO/CAP HER2 Testing in Breast Cancer 2013 Update. Additional information regarding this survey process is available in the Data Supplement.

The Expert Panel met during a 2-day in-person meeting in November 2016 to consider the evidence for each of the recommendations contained in this 2018 Focused Update. Laboratories that shared with the

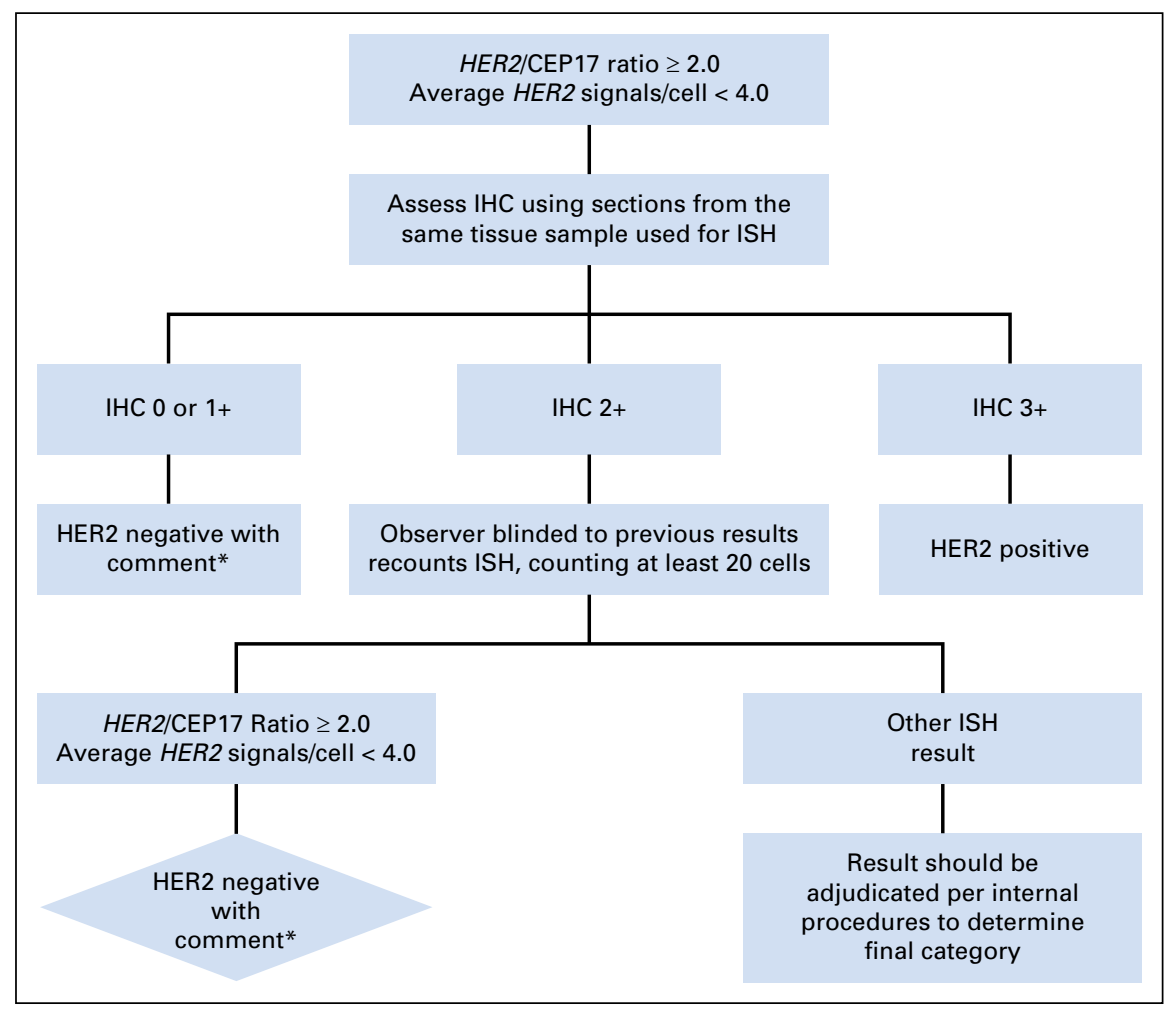

Fig 4. Clinical Question 3, group 2. $(*)$ Evidence is limited on the efficacy of HER2-targeted therapy in the small subset of cases with a HER2/CEP17 ratio $\geq 2.0$ and an average HER2 copy number of $<4.0$ per cell. In the first generation of adjuvant trastuzumab trials, patients in this subgroup who were randomly assigned to the trastuzumab arm did not seem to derive an improvement in disease-free or overall survival, but there were too few such cases to draw definitive conclusions. IHC expression for HER2 should be used to complement ISH and define HER2 status. If the IHC result is not 3+ positive, it is recommended that the specimen be considered HER2 negative because of the low HER2 copy number by ISH and the lack of protein overexpression. CEP17, chromosome enumeration probe 17; HER2, human epidermal growth factor receptor 2; IHC, immunohistochemistry; ISH, in situ hybridization. 


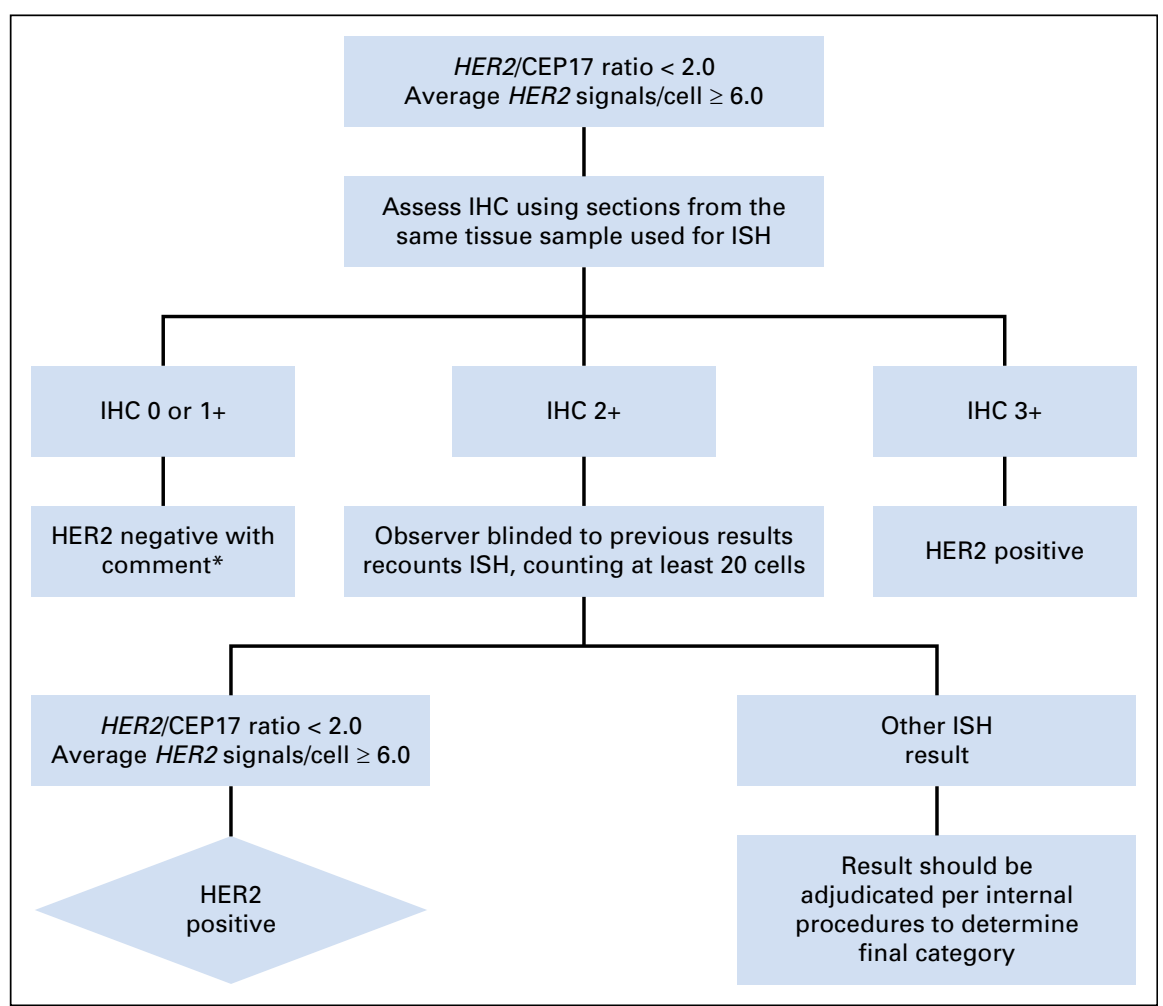

Fig 5. Clinical Question 4, group 3. (*) There are insufficient data on the efficacy of HER2-targeted therapy in cases with a HER2 ratio of $<2.0$ in the absence of protein overexpression because such patients were not eligible for the first generation of adjuvant trastuzumab clinical trials. When concurrent $\mathrm{IHC}$ results are negative ( 0 or $1+$ ), it is recommended that the specimen be considered HER2 negative. CEP17, chromosome enumeration probe 17; HER2, human epidermal growth factor receptor 2; IHC, immunohistochemistry; ISH, in situ hybridization.

Expert Panel their clinical experience with HER2 testing since the publication of the 2013 Guideline Update participated in the open session of the meeting. The guideline was circulated in draft form to the Expert Panel. Draft recommendations were released to the public for an open comment period between May 22 and June 19, 2017. ASCO's
Clinical Practice Guidelines Committee reviewed and approved the final document. For CAP, an independent review panel was assembled to review and approve the guideline. The independent review panel was masked to the Expert Panel and was vetted through the conflict of interest process.

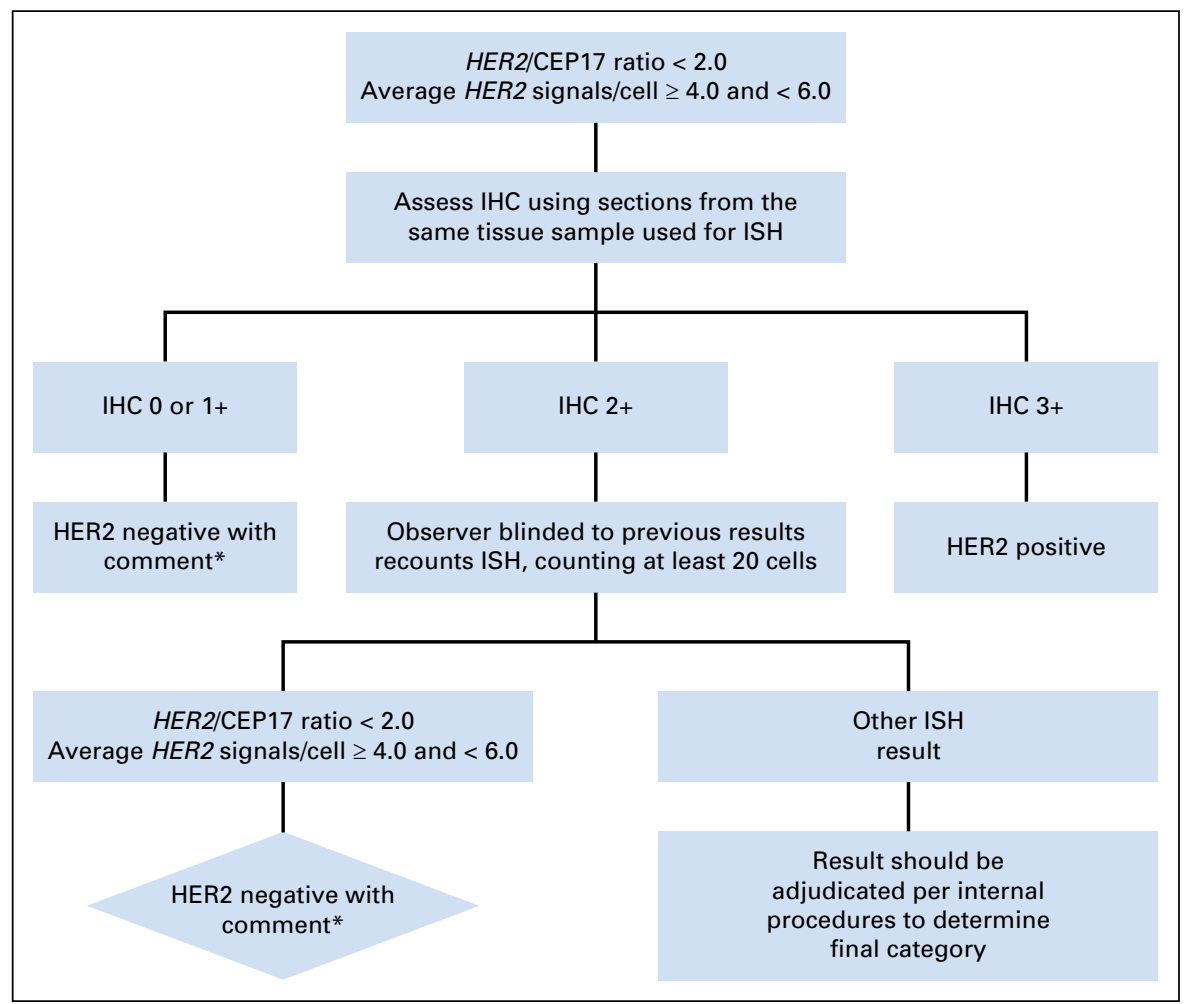

Fig 6. Clinical Question 5, group 4. $\left(^{*}\right)$ It is uncertain whether patients with an average of $\geq 4.0$ and $<6.0$ HER2 signals per cell and a HER2/CEP17 ratio of $<2.0$ benefit from HER2-targeted therapy in the absence of protein overexpression (IHC $3+$ ). If the specimen test result is close to the ISH ratio threshold for positive, there is a higher likelihood that repeat testing will result in different results by chance alone. Therefore, when $\mathrm{IHC}$ results are not $3+$ positive, it is recommended that the sample be considered HER2 negative without additional testing on the same specimen. CEP17, chromosome enumeration probe 17; HER2, human epidermal growth factor receptor 2; IHC, immunohistochemistry; ISH, in situ hybridization. 
Table 3. Distribution by Dual FISH and IHC Testing Results in Reported Data Sets

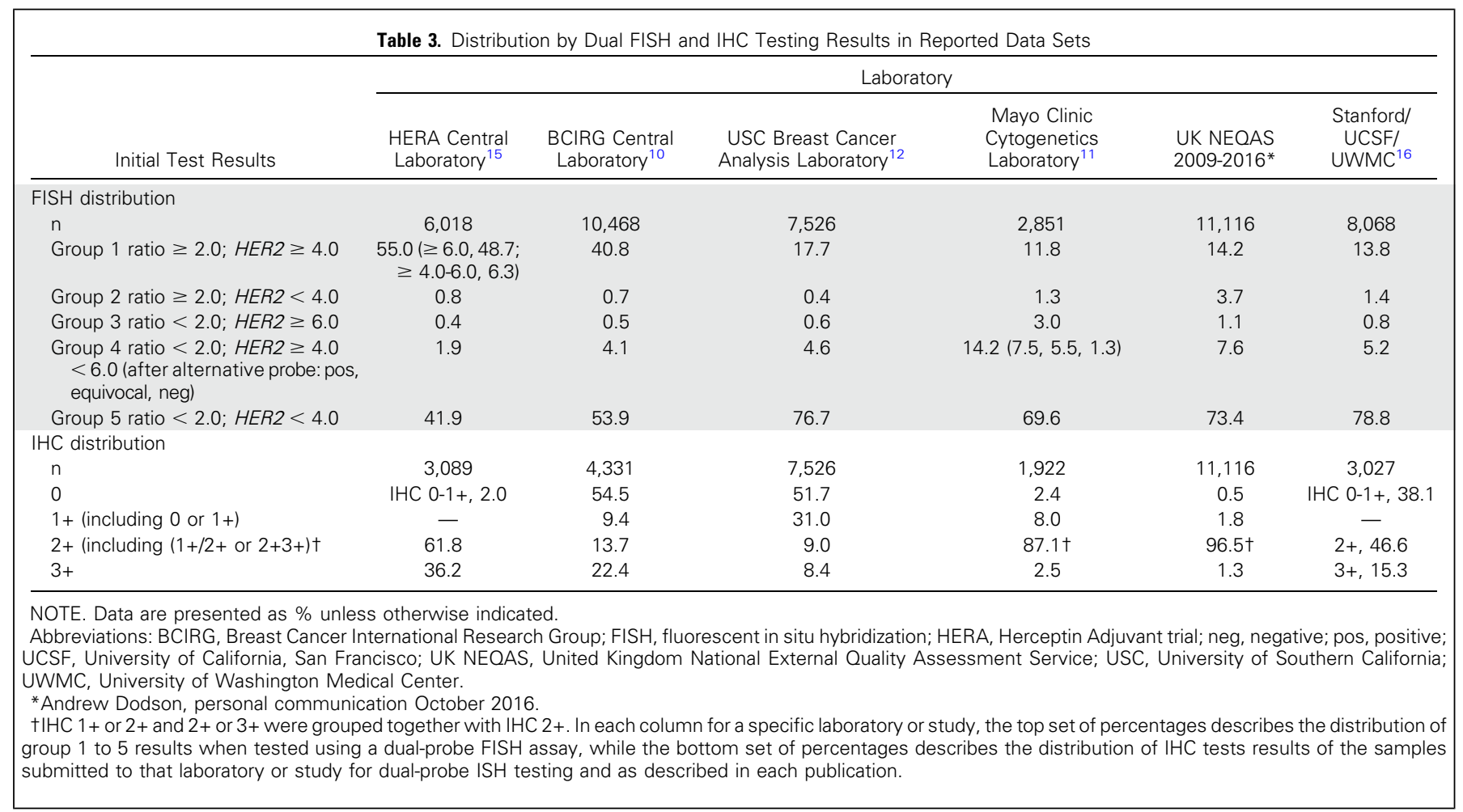

Only recommendations relating to the updated clinical questions have changed. The Data Supplement provides clinical questions corresponding to all recommendations from the 2013 Guideline Update.

This ASCO/CAP Clinical Practice Guideline Focused Update provides select recommendations with a comprehensive discussion of the relevant literature from January 1, 2013, to May 11, 2017, for these specific recommendations. The full guideline, which this revision applies to, and additional information are available at www.asco.org/ breast-cancer-guidelines. The complete list of recommendations, including the updated recommendations, is in Table 1. All funding for the administration of the project was provided by ASCO and CAP.

\section{Guideline Disclaimer}

The clinical practice guidelines and other guidance published herein are provided by the American Society of Clinical Oncology, Inc. ("ASCO") to assist providers in clinical decision making. The information therein should not be relied upon as being complete or accurate, nor should it be considered as inclusive of all proper treatments or methods of care or as a statement of the standard of care. With the rapid development of scientific knowledge, new evidence may emerge between the time information is developed and when it is published or read. The information is not continually updated and may not reflect the most recent evidence. The information addresses only the topics specifically identified therein and is not applicable to other interventions, diseases, or stages of diseases. This information does not mandate any particular course of medical care. Further, the information is not intended to substitute for the independent professional judgment of the treating provider, as the information does not account for individual variation among patients. Recommendations reflect high, moderate or low confidence that the recommendation reflects the net effect of a given course of action. The use of words like "must," "must not," "should," and "should not" indicate that a course of action is recommended or not recommended for either most or many patients, but there is latitude for the treating physician to select

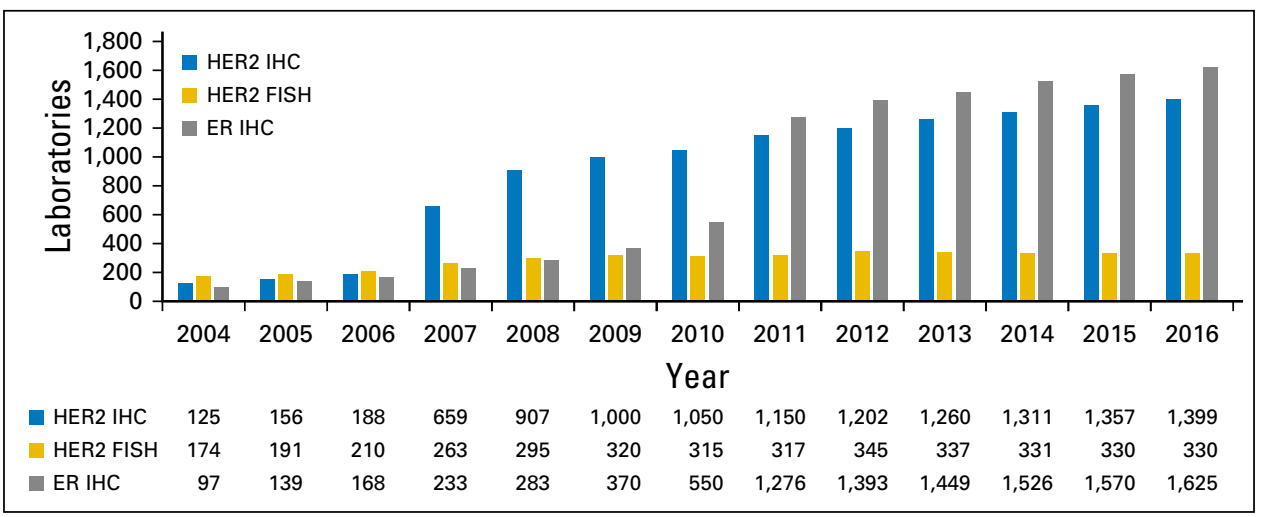

Fig 7. Number of laboratories participating in predictive marker proficiency testing for human epidermal growth factor receptor 2 (HER2) by immunohistochemistry (IHC), HER2 by fluorescent in situ hybridization (FISH), and estrogen receptor (ER) by $\mathrm{IHC}$ through the College of American Pathologists Laboratory Improvement Program. 
other courses of action in individual cases. In all cases, the selected course of action should be considered by the treating provider in the context of treating the individual patient. Use of the information is voluntary. ASCO provides this information on an "as is" basis, and makes no warranty, express or implied, regarding the information. ASCO specifically disclaims any warranties of merchantability or fitness for a particular use or purpose. ASCO assumes no responsibility for any injury or damage to persons or property arising out of or related to any use of this information or for any errors or omissions.

\section{Guideline and Conflicts of Interest}

The Expert Panel was assembled in accordance with ASCO's Conflict of Interest Policy Implementation for Clinical Practice Guidelines ("Policy," found at http://www.asco.org/rwc) as agreed upon with CAP. All members of the Expert Panel completed ASCO's disclosure form, which requires disclosure of financial and other interests, including relationships with commercial entities that are reasonably likely to experience direct regulatory or commercial impact as a result of promulgation of the guideline. Categories for disclosure include employment; leadership; stock or other ownership; honoraria, consulting or advisory role; speaker's bureau; research funding; patents, royalties, other intellectual property; expert testimony; travel, accommodations, expenses; and other relationships. In accordance with the Policy, the majority of the members of the Expert Panel did not disclose any relationships constituting a conflict under the Policy.

\section{RECOMMENDATIONS}

All recommendations regarding each of the five clinical questions are predicated on the assumption that the cases have been properly fixed, processed, and tested in a laboratory that follows ASCO/CAP HER2 testing guideline recommendations, especially those related to IHC and ISH interpretation and reporting.

In the 2013 Guideline Update, the work-up of cases in the less common dual-probe ISH categories (groups 2 to 4) addressed in Clinical Questions 3, 4, and 5 (Fig 3) included only ISH. In this 2018 Focused Update, we recommend that these cases be worked up by considering both the IHC and the dual-probe ISH results together. Many publications since the 2013 Guideline Update have referenced the value of adjudicating ISH results in these uncommon categories using IHC. ${ }^{12,16,19-21}$ These tests should be performed on the same tissue sample using sections from the same block. Ideally, adjacent tissue levels from the same block should be tested and then reviewed together. If IHC has already been performed, it should be used to guide the selection of the areas to be counted during ISH such that areas with the strongest protein expression can be included in ISH scoring. This is common practice among laboratories performing both testing procedures. If the ISH laboratory only performs ISH, it is recommended that an adjacent section in the same block be assessed at a companion IHC laboratory, and then the slides from both ISH and IHC be reviewed together to guide the selection of areas to score by ISH. Local practice considerations will dictate the best procedure to accomplish this concomitant review.

\section{Clinical Question 1}

What is the most appropriate definition for IHC 2+ (IHC equivocal)?
2013 recommendation. IHC $2+$ (equivocal) was defined in Figure 1 of the 2013 HER2 Testing Update as invasive breast cancer showing "circumferential membrane staining that is incomplete and/or weak/moderate and within $>10 \%$ of tumor cells or complete and circumferential membrane staining that is intense and within $\leq 10 \%$ of tumor cells."

Revised 2018 recommendation. In the revised Figure 1, the revised definition of IHC $2+$ (equivocal) is invasive breast cancer with "weak to moderate complete membrane staining observed in $>10 \%$ of tumor cells" (Type: evidence based; Evidence quality: high; Strength of recommendation: strong).

Literature review and analysis. IHC $2+$ (equivocal) had been defined in the 2013 Guideline Update (2013 Fig 1: Algorithm for evaluation of HER2 protein expression by IHC assay of the invasive component of a breast cancer specimen) as invasive breast cancer showing "circumferential membrane staining that is incomplete and/or weak/moderate and within $>10 \%$ of tumor cells or complete and circumferential membrane staining that is intense and within $\leq 10 \%$ of tumor cells." However, many pathologists expressed concern that the terms "circumferential" and "incomplete" were confusing, could not be reconciled when used together in the IHC interpretation of HER2 expression, and could lead to many IHC 1+ (HER2-negative) tumors being called IHC 2+ (HER2 equivocal) and submitted for reflex testing.

In the same Figure 1 of the 2013 Guideline Update, the statement "complete and circumferential membrane staining that is intense and within $\leq 10 \%$ of tumor cells" referred to an unusual pattern that did not need to be specified in the main portion of the figure. This information has now been moved to the footnote of Figure 1, which will now read as follows: "Unusual staining patterns of HER 2 by IHC can be encountered that are not covered by these definitions. In practice, these patterns are rare and if encountered should be considered IHC 2+ equivocal. As one example, some specific subtypes of breast cancers can show IHC staining that is moderate to intense but incomplete (basolateral or lateral) and can be found to be HER2 amplified. ${ }^{22}$ Another example is circumferential membrane IHC staining that is intense but within $\leq 10 \%$ of tumor cells (heterogeneous but very limited in extent)."

Consequently, the revised definition of IHC 2+ (HER2 equivocal) in this 2018 Focused Update (Fig 1) reflects a commonly accepted definition of invasive breast cancer that now reads "weak to moderate complete membrane staining observed in $>10 \%$ of tumor cells". ${ }^{23}$ During the open comment period, pathologists requested guidance about the uncommon scenario of cases in which "intense circumferential membrane staining is observed in $\leq 10 \%$ of tumor cells." As described in the footnote in Figure 1, such cases may be considered IHC 2+ equivocal, although additional samples may reveal different percentages of HER2-positive staining. These revisions were previously communicated in a 2015 correspondence from the ASCO/CAP HER2 testing Expert Panel published in $\mathrm{JCO}^{14}$

\section{Clinical Question 2}

Must HER2 testing be repeated on a surgical specimen if initially negative test on core biopsy? 
2013 recommendation. In Table 2 in the 2013 HER 2 testing Update, it was stated that, on the basis of some criteria (including a tumor grade 3), "If the initial HER2 test result in a core needle biopsy specimen of a primary breast cancer is negative, a new HER2 test must be ordered on the excision specimen . . ..

Revised 2018 recommendation. In the revised Table 2, it is now stated that, on the basis of some criteria (including a tumor grade 3 ), "If the initial HER2 test result in a core needle biopsy specimen of a primary breast cancer is negative, a new HER2 test may be ordered on the excision specimen ..." (Type: evidence based; Evidence quality: high; Strength of recommendation: strong).

Literature review and analysis. The auxiliary verb "must" was used in the 2013 Guideline Update (Table 2) ${ }^{1}$ to indicate that, on the basis of some criteria (including a tumor grade 3 ), "If the initial HER2 test result in a core needle biopsy specimen of a primary breast cancer is negative, a new HER2 test must be ordered on the excision specimen ...."

The Expert Panel had previously indicated in the Data Supplement of the 2013 Guideline Update that "smaller datasets from several investigators seemed to suggest that it might be possible to identify subsets where the level of suspicion of false negativity is markedly raised. However, many of these criteria are consistent with true triple-negative disease, and the (2013) Update Committee was unsure whether re-testing was indicated for all such cancers (and) ... w was unable to identify a specific subgroup that would benefit from mandatory reflex testing if IHC is less than $2+$." Several data sets originally referenced in 2013 showed excellent concordance for HER2 testing in paired samples (core biopsy specimen and excision) using IHC as the initial test, such as a $98.8 \%$ concordance observed among 336 patients in the Royal Marsden experience. ${ }^{24}$

Rakha et al, ${ }^{17}$ in their 2015 correspondence to JCO, described their own institutional experience and that of other groups, including many previously described in the 2013 Guideline Update. In its 2015 response $^{14}$ to the correspondence by Rakha et $\mathrm{al},{ }^{17}$ the Expert Panel agreed that, in view of the greater clinical experience that confirmed the high concordance in HER2 testing between core and excisional biopsies, it was appropriate to allow the pathologist and oncologist to exercise clinical judgment and that grade 3 alone did not suffice as a criterion for mandatory retesting.

Therefore, in the revised Table 2, the auxiliary verb "must" has been replaced by "may" to indicate that "If the initial HER2 test result in a core needle biopsy specimen of a primary breast cancer is negative, a new HER2 test may be ordered on the excision specimen..." These changes are the same as those previously communicated in a 2015 correspondence by the authors of the 2013 Guideline Update and published in JCO. ${ }^{14}$

\section{Clinical Question 3}

Should invasive cancers with a HER2/CEP17 ratio of $\geq 2.0$ but an average HER2 copy number of $<4.0$ signals per cell be considered ISH positive?

2013 recommendation. Cases in which the HER2/CEP17 ratio is $\geq 2.0$ with an average HER2 signals per cell of $<4.0$ were considered ISH positive.
Revised 2018 recommendation. If a case has a HER2/CEP17 ratio of $\geq 2.0$ but the average HER2 signals per cell is $<4.0$, a definitive diagnosis will be rendered based on additional workup.

If not already assessed by the institution or laboratory performing the ISH test, IHC testing for HER2 should be performed using sections from the same tissue sample used for ISH, and the slides from both ISH and IHC should be reviewed together to guide the selection of areas to score by ISH (local practice considerations will dictate the best procedure to accomplish this concomitant review):

If the IHC result is $3+$, diagnosis is HER2 positive.

If the IHC result is $2+$, recount ISH by having an additional observer, blinded to previous ISH results, count at least 20 cells that include the area of invasive cancer with IHC $2+$ staining:

- If reviewing the count by the additional observer changes the result into another ISH category, the result should be adjudicated per internal procedures to define the final category.

- If the count remains an average of $<4.0$ HER2 signals per cell and the HER2/CEP17 ratio is $\geq 2.0$, diagnosis is HER2 negative with a comment.

If the IHC result is 0 or $1+$, diagnosis is HER2 negative with a comment.

The Expert Panel recommends the following comment: Evidence is limited on the efficacy of HER2-targeted therapy in the small subset of cases with a HER2/CEP17 ratio of $\geq 2.0$ and an average HER 2 copy number of $<4.0$ per cell. In the first generation of adjuvant trastuzumab trials, patients in this subgroup who were randomly assigned to the trastuzumab arm did not seem to derive an improvement in disease-free or overall survival, but there were too few such cases to draw definitive conclusions. IHC expression for HER2 should be used to complement ISH and define HER2 status. If the IHC result is not $3+$ positive, it is recommended that the specimen be considered HER2 negative because of the low HER2 copy number by ISH and the lack of protein overexpression.

(Type: evidence based; Evidence quality: intermediate; Strength of recommendation: strong). An algorithm for Clinical Question 3 is presented in Figures 3 and 4.

Literature review and analysis. Members of the HER2 testing Expert Panel in 2013 had expressed concern about describing an invasive breast cancer as HER2 positive on the basis of a single HER2 ISH test that showed a HER2/CEP17 ratio of $\geq 2.0$ but an average HER2 copy number of $<4.0$ signals per cell (Fig 3, group 2 ) and recommended additional testing of such cases. Members of the 2013 Guideline Update Panel also expressed their view that using the HER2/CEP17 ratio alone could be misleading in cases with CEP17 gains or losses and could lead to an under- or overestimation of HER2 amplification. However, the eligibility criteria for the first adjuvant trials of trastuzumab generally followed US Food and Drug Administration criteria (IHC 3+ or ISH ratio $\geq 2.0$ regardless of average HER2 copy number based on HER2 signals per cell), and the Expert Panel in 2013 ultimately 
opted to consider these rare group 2 patients as having HER2positive disease.

Since then, investigators have further reported on the outcome of patients with a group 2 dual-probe ISH test result. Greater experience and a more refined collection of test results in the past few years confirmed that such cases are infrequent (Table 3) and represented a small number of patients enrolled in the initial adjuvant trastuzumab trials. Among 4,340 patients $(41.5 \%$ of $10,468)$ screened by dual-probe fluorescent ISH (FISH) for trials BCIRG-005 (HER2 negative trial) and 006 (HER2 positive trial) and found to have a dual-probe ISH ratio of $\geq 2.0$, only $71(0.7 \%$ of 10,468) had an average HER2 signals per cell of $<4.0 .^{10}$ Furthermore, in 35 of these 71 patients who were also tested later by IHC, only three were IHC $2+$ and none were IHC $3+$. A retrospective assessment of potential benefit from trastuzumab in group 2 patients produced an observed hazard ratio estimate of slightly $>1.0$ (favoring no trastuzumab benefit), but the sample size was insufficient to statistically rule out a benefit from adjuvant trastuzumab in this group; nor could it be established statistically whether group 2 patients not treated with trastuzumab had outcomes different from patients with HER2-negative disease treated with just chemotherapy. ${ }^{10}$ In the HERA trial, group 2 patients were also uncommon $(0.8 \%)$ among all patients centrally screened for eligibility (Table 3), while group 1 patients (ISH ratio $\geq 2.0$ and average HER2 signals per cell of $\geq 4.0$ ) represented $55 \%$ of all tested cases $(48.7 \% \geq 6.0$ and $6.3 \% \geq 4.0$ and $<6.0) .{ }^{15}$ In summary, the Expert Panel concluded that these group 2 cases should no longer be considered HER2 positive unless IHC 3+ overexpressed.

Repeat testing of other tissue samples from the patient may also be appropriate in this setting, and in particularly challenging cases or if the results are in question, expert consultation may be appropriate.

\section{Clinical Question 4}

Should invasive cancers with an average HER2 copy number of $\geq 6.0$ signals per cell but a HER2/CEP17 ratio of $<2.0$ be considered ISH positive?

2013 recommendation. Cases in which the HER2/CEP17 ratio is $<2.0$ with an average of $\geq 6.0$ HER2 signals per cell were considered ISH positive.

Revised 2018 recommendation. If a case has an average of $\geq 6.0$ HER2 signals per cell with a HER2/CEP17 ratio of $<2.0$, formerly diagnosed as ISH positive for HER2, a definitive diagnosis will be rendered based on additional work-up.

If not already assessed by the institution or laboratory performing the ISH test, IHC testing for HER2 should be performed using sections from the same tissue sample used for ISH, and the slides from both ISH and IHC should be reviewed together to guide the selection of areas to score by ISH (local practice considerations will dictate the best procedure to accomplish this concomitant review):

If the IHC result is $3+$, diagnosis is HER2 positive.

If the IHC result is $2+$, recount ISH by having an additional observer, blinded to previous ISH results, count at least 20 cells that include the area of invasion with IHC $2+$ staining:
- If reviewing the count by the additional observer changes the result into another ISH category, the result should be adjudicated per internal procedures to define the final category.

- If the HER2/CEP17 ratio remains $<2.0$ with $\geq 6.0$ HER2 signals per cell, diagnosis is HER2 positive.

If the IHC result is 0 or $1+$, diagnosis is HER2 negative with a comment.

The Expert Panel recommends the following comment: There are insufficient data on the efficacy of HER2-targeted therapy in cases with a HER2 ratio of $<2.0$ in the absence of protein overexpression because such patients were not eligible for the first generation of adjuvant trastuzumab clinical trials. When concurrent IHC results are negative ( 0 or $1+)$, it is recommended that the specimen be considered HER2 negative.

(Type: evidence based; Evidence quality: intermediate; Strength of recommendation: strong). An algorithm for Clinical Question 4 is presented in Figures 3 and 5.

Literature review and analysis. Based on available data, samples with ISH results in this category (ratio $<2.0$ and mean HER2 signals per cell $\geq 6.0$ ) are uncommon, only representing between $0.4 \%$ and $3.0 \%$ of cases sent for dual-probe FISH testing (Table 3). These ISH cases have increases in both HER2 and control centromere signals, resulting in ratio results of $<2.0$. At the time of the pivotal HER2 trials, cases with these results were considered to have duplication of CEP17 (polysomy) and were most often excluded because they were considered negative for HER2 gene amplification, although Breast Cancer International Research Group (BCIRG-006; Clinicaltrials.gov identifier: NCT00021255) allowed patients to be enrolled if the HER2 copy number was $\geq 10$ and central IHC testing was $3+$. Subsequent studies examining multiple regions of chromosome 17 supported that the majority of cases with these results have HER2 amplifications that include regions encompassing the centromere rather than true polysomy for the entire chromosome 17 (coamplification of control and HER2 signals). ${ }^{25-31}$ Based on these data, the 2013 Guideline Update clarified that cases with an average HER 2 copy number of $\geq 6.0$ HER 2 signals per cell ISH results (by either single- or dual-probe assays) should be reported as HER2 positive by gene amplification. However, it was acknowledged that data on the clinical response of this group to HER2 targeted therapies were limited.

Since the 2013 update, additional data have been published including concurrent IHC results for this ISH category, and they show that this group can be heterogeneous. Data from a reanalysis of the HERA trial identified a small number of cases (21 total) originally considered negative due to ratios of $<2.0$ but with an average of $\geq 6.0$ HER2 signals per cell. ${ }^{15}$ All of these cases had $>3$ mean CEP17 signals per cell, and 75\% of them (15 of 20) had HER2 overexpression by IHC. In a combined study of three major academic medical centers performing HER2 FISH and IHC, similar results were seen with 63 cases in this ISH category; $31.7 \%$ were IHC $3+$ for HER2 by IHC, 55\% were IHC 2+, and 13.7\% were IHC 0 or $1+{ }^{16}$ This study also reported a higher frequency of Nottingham grade 3 cancers with these ISH results than with other ISH result categories. Published data from a reference laboratory at the University of Southern California described 48 
cases with the same ISH characteristics and found that only $8.3 \%$ were IHC $3+$, while $14.6 \%$ were IHC $2+$ and $77 \%$ were IHC 0 or $1+{ }^{12}$ Additional analysis of these cases identified a highly amplified subgroup (eight total cases) with an average of 12.3 HER2 signals per cell that correlated well with HER2 IHC $2+$ or $3+(75 \%)$. This subgroup differed significantly from the other subgroup (40 total cases) that had a lower average of 6.8 HER2 signals per cell and $87.5 \%$ IHC negative (0 or $1+$ ) results. Similarly, in the Breast Cancer International Research Group central testing clinical trial data, of the limited cases (nine total) with IHC data and $\mathrm{ISH}$ results in this category, one was IHC $3+$ positive, one was IHC $2+$, and seven were IHC negative. ${ }^{10}$ Taken together, these results suggest that cases in this ISH category form a heterogeneous group that is best discriminated by the combination of IHC and ISH.

Due to the rarity of cases with these ISH results, there is still limited clinical evidence regarding benefit from HER2-targeted therapy. The BCIRG-005 data (no HER2-targeted treatment) indicated a worse disease-free and overall survival for this ISH category than for cases with both a HER2/CEP17 ratio of $<2.0$ and $<4.0$ signals per cell (ISH nonamplified). ${ }^{10}$ However, the few cases enrolled in the BCIRG-006 adjuvant trastuzumab trial with these ISH results were insufficient to assess whether there was benefit from HER2-targeted therapy, and statistical analysis was not attempted.

Overall, the absence of robust clinical data to guide decisions, and the variability in IHC data, support the concept that protein expression results should be used concurrently in this setting to aid in determining the significance of ISH results. In summary, group 3 cases are uncommon and heterogeneous. Based on available data, the ratio may not be a reliable indicator of the true gene amplification status. ${ }^{25-31}$ Given the evidence that some group 3 cases have true HER2 amplification rather than polysomy for chromosome 17, particularly when the HER2 copy number is high, the Expert Panel ultimately favored continuing to classify these cases as HER2 positive unless the concurrent IHC result is clearly negative $(0 \text { or } 1+)^{25-31}$

Repeat testing of other tissue samples from the patient may also be appropriate in this setting and, in particularly challenging cases or if the results are in question, expert consultation may be appropriate and include alternative probes or other genetic methods. ${ }^{11}$ However, alternative probes should not be used as standard practice in view of the absence of outcome data.

\section{Clinical Question 5}

What is the appropriate diagnostic work-up for invasive cancers with an average HER 2 copy number of $\geq 4.0$ but $<6.0$ signals per cell and a HER2/CEP17 ratio of $<2.0$ and initially deemed to have an equivocal HER2 ISH test result?

2013 recommendation. Cases in which the HER2/CEP17 ratio is $<2.0$ with an average HER 2 copy number of $\geq 4.0$ and $<6.0$ signals per cell were considered ISH equivocal, and additional work-up was required ("Must order a reflex test [same specimen using IHC], test with alternative ISH chromosome 17 probe, or order a new test [new specimen if available, ISH or IHC]”).
Revised 2018 recommendation. If the case has an average HER2 signals per tumor cell of $\geq 4.0$ and $<6.0$ and the HER2/ CEP17 ratio is $<2.0$, formerly diagnosed as ISH equivocal for HER2, a definitive diagnosis will be rendered based on additional work-up.

If not already assessed by the institution or laboratory performing the ISH test, IHC testing for HER2 should be performed using sections from the same tissue sample used for ISH, and the slides from both ISH and IHC should be reviewed together to guide the selection of areas to score by ISH (local practice considerations will dictate the best procedure to accomplish this concomitant review):

If the IHC result is $3+$, diagnosis is HER2 positive.

If the IHC result is $2+$, recount ISH by having an additional observer, blinded to previous ISH results, count at least 20 cells that include the area of invasion with IHC 2+ staining:

- If reviewing the count by the additional observer changes the result into another ISH category, the result should be adjudicated per internal procedures to define the final category.

- If the count remains an average of $\geq 4.0$ and $<6.0$ HER2 signals per cell with a HER2/CEP17 ratio of $<2.0$, diagnosis is HER2 negative with a comment.

If the IHC result is 0 or $1+$, diagnosis is HER2 negative with a comment.

The Expert Panel recommends the following comment: It is uncertain whether patients with an average of $\geq 4.0$ and $<6.0$ HER2 signals per cell and a HER2/CEP17 ratio of $<2.0$ benefit from HER 2 targeted therapy in the absence of protein overexpression (IHC 3+). If the specimen test result is close to the ISH ratio threshold for positive, there is a high likelihood that repeat testing will result in different results by chance alone. Therefore, when IHC results are not $3+$ positive, it is recommended that the sample be considered HER2 negative without additional testing on the same specimen).

(Type: evidence based; Evidence quality: intermediate; Strength of recommendation: strong). An algorithm for Clinical Question 5 is presented in Figures 3 and 6.

Literature review and discussion. Cases with an average of $\geq 4.0$ and $<6.0$ HER2 signals per cell and a HER2/CEP17 ratio of $<2.0$ were considered equivocal in the 2013 Guideline Update. This category (group 4 cases) has been reconsidered by the Expert Panel based on published literature since then, and was discussed by the representatives of expert laboratories and Expert Panel members during the open portion of the November 2016 inperson meeting. In many published studies, the incidence of equivocal cases has changed since the 2013 update, when more stringent requirements for ISH interpretation were described. ${ }^{1,4}$ The number of such cases within a laboratory varies based on the patient population referred for ISH testing, but it seems to be approximately $5 \%$ of cases (range, $1 \%$ to $16 \%$ ). ${ }^{15,19-21,32-42}$ The use of alternative probes to adjudicate these cases has also increased since 2013.

Data from a central reference laboratory at Mayo Clinic included FISH data in a population of patients that is enriched from those with HER2 IHC 2+ results based on the original IHC testing performed locally by the referring laboratories (1,922 patients; $85 \%$ IHC 2+). Among these cases tested by FISH at Mayo, $14 \%$ of 
patients had ISH equivocal results and one half became HER2 positive by ratio when a locally developed and analytically validated 17 p arm probe (D17S122; Mayo Clinic, Rochester, MN) was combined with the HER2 probe (Abbott Molecular, Abbott Park, IL) for additional FISH testing. However, clinical information about benefit from HER2-targeted therapy in such patients is not available and may not exist because these patients would not have been eligible for the original pivotal trials. ${ }^{11}$ The reference laboratory experience reported by Press et $\mathrm{al}^{12}$ involving a different patient population found $4.6 \%$ of patients among 7,526 cases with equivocal results if using the 2013 criteria; while $89 \%$ of these cases were IHC HER 20 or $1+, 10 \%$ were IHC HER $2+$, and only $0.9 \%$ were IHC HER2 $3+$ positive. Another academic laboratory experience that combined results from three laboratories had a similar frequency of numbers of specimens with equivocal results (5.2\%) among 8,068 patients. Similar clinical characteristics were observed in patients with an average of $\geq 4.0$ and $<6.0$ HER2 signals per cell, regardless of whether the ratio was above or below 2.0, and most of these cases were HER2 negative by IHC and more likely to be estrogen receptor positive. ${ }^{16}$

Group 4 cases reported as HER2 equivocal since the 2013 Guideline Update have posed a challenge to oncologists and patients due to a perceived ambivalence about whether to recommend HER2-targeted therapy. In the absence of an unequivocally positive or negative test result, multiple testing of the same tissue sample has been performed frequently, and many laboratories have relied exclusively on alternative probe testing to resolve cases that are more difficult. This has often included ISH testing using multiple chromosome 17 probes at once, many not analytically or clinically validated. Such indiscriminate testing often results in four or more ISH ratios being described in a single test report and a final designation of HER2 gene amplified if just a single ratio is $\geq 2.0$. After careful consideration of this practice and available data, the Expert Panel strongly recommends against this as a routine testing strategy. When the HER2 ratio score is near a decision threshold (positive or negative), based on random variation in scoring, a subsequent test may result in a positive or negative score barely crossing the threshold (on either side). In such cases, repeated ISH testing may therefore not result in higher confidence in the final result.

Clinical correlation with other factors in a particular case (such as grade and special histologic subtypes) or repeat testing of other tissue samples from the patient may also be appropriate in this setting. In particularly challenging cases or if the results are in question, expert consultation may be appropriate and may include alternative probes or other genetic methods. ${ }^{11}$ However, alternative probes should not be used as standard practice due to limited data on outcomes for this subset of patients. ${ }^{33}$

\section{ADDITIONAL RESOURCES}

Additional information including data supplements, evidence tables, and clinical tools and resources can be found at www.asco. org/breast-cancer-guidelines. Patient information is available there and at www.cancer.net.

\section{Related ASCO Guidelines}

- Use of Biomarkers to Guide Decisions on Adjuvant Systemic Therapy for Women With Early-Stage Invasive Breast Cancer ${ }^{43}$ (http://ascopubs.org/doi/10.1200/ JCO.2017.74.0472)

- Selection of Optimal Adjuvant Chemotherapy Regimens for Human Epidermal Growth Factor Receptor 2 (HER2)-Negative and Adjuvant Targeted Therapy for HER2-Positive Breast Cancer ${ }^{44}$ (http://ascopubs.org/ doi/10.1200/JCO.2016.67.0182)

- Role of Patient and Disease Factors in Adjuvant Systemic Therapy Decision Making for Early-Stage Operable Breast Cancer ${ }^{45}$ (http://ascopubs.org/doi/10.1200/ JCO.2015.65.8609)

- Use of Biomarkers to Guide Decisions on Systemic Therapy for Women With Metastatic Breast Cancer ${ }^{46}$ (http://ascopubs.org/doi/10.1200/JCO.2015.61.1459)

- Chemotherapy and Targeted Therapy for Women With Human Epidermal Growth Factor Receptor 2-Negative (or unknown) Advanced Breast Cancer ${ }^{47}$ (http:// ascopubs.org/doi/10.1200/JCO.2014.56.7479)

- Systemic Therapy for Patients With Advanced Human Epidermal Growth Factor Receptor 2-Positive Breast Cancer $^{48}$ (http://ascopubs.org/doi/10.1200/ JCO.2013.54.0948)

- Recommendations on Disease Management for Patients With Advanced Human Epidermal Growth Factor Receptor 2-Positive Breast Cancer and Brain Metastases $^{49}$ (http://ascopubs.org/doi/10.1200/ JCO.2013.54.0955)

- Immunohistochemical Testing of Estrogen and Progesterone Receptors in Breast Cancer ${ }^{50}$ (http:// ascopubs.org/doi/10.1200/JCO.2009.25.6529)

\section{AUTHORS' DISCLOSURES OF POTENTIAL CONFLICTS OF INTEREST}

Disclosures provided by the authors are available with this article at jco.org.

\section{AUTHOR CONTRIBUTIONS}

Manuscript writing: All authors

Final approval of manuscript: All authors

Accountable for all aspects of the work: All authors 


\section{REFERENCES}

1. Wolff $A C$, Hammond $M E$, Hicks $D G$, et al: Recommendations for human epidermal growth factor receptor 2 testing in breast cancer: American Society of Clinical Oncology/College of American Pathologists clinical practice guideline update. J Clin Oncol 31:3997-4013, 2013

2. Wolff $A C$, Hammond ME, Schwartz JN, et al: American Society of Clinical Oncology/College of American Pathologists guideline recommendations for human epidermal growth factor receptor 2 testing in breast cancer. J Clin Oncol 25:118-145, 2007

3. Wolff $\mathrm{AC}$, Hammond ME, Schwartz JN, et al: American Society of Clinical Oncology/College of American Pathologists guideline recommendations for human epidermal growth factor receptor 2 testing in breast cancer. Arch Pathol Lab Med 131:18-43, 2007

4. Wolff AC, Hammond ME, Hicks DG, et al: Recommendations for human epidermal growth factor receptor 2 testing in breast cancer: American Society of Clinical Oncology/College of American Pathologists clinical practice guideline update. Arch Pathol Lab Med 138:241-256, 2014

5. Ma CX, Bose R, Gao F, et al: Neratinib efficacy and circulating tumor DNA detection of HER2 mutations in HER2 nonamplified metastatic breast cancer. Clin Cancer Res 23:5687-5695, 2017

6. Fehrenbacher L, Cecchini RS, Geyer CE, et al: NSABP B-47 (NRG oncology): Phase III randomized trial comparing adjuvant chemotherapy with adriamycin (A) and cyclophosphamide (C) $\rightarrow$ (A) weekly paclitaxel (WP), or docetaxel (T) and $\mathrm{C}$ with or without a year of trastuzumab $(H)$ in women with nodepositive or high-risk node-negative invasive breast cancer (IBC) expressing HER2 staining intensity of IHC 1+ or 2+ with negative FISH (HER2-Low IBC). Presented at San Antonio Breast Cancer Symposium, December 5-9, 2017 San Antonio, TX

7. Middleton LP, Price KM, Puig P, et al: Implementation of American Society of Clinical Oncology/ College of American Pathologists HER2 guideline recommendations in a tertiary care facility increases HER2 immunohistochemistry and fluorescence in situ hybridization concordance and decreases the number of inconclusive cases. Arch Pathol Lab Med 133:775-780, 2009

8. Rakha EA, Pinder SE, Bartlett JM, et al: Updated UK recommendations for HER2 assessment in breast cancer. J Clin Pathol 68:93-99, 2015

9. Hanna WM, Barnes PJ, Chang $M C$, et al: Human epidermal growth factor receptor 2 testing in primary breast cancer in the era of standardized testing: A Canadian prospective study. J Clin Oncol 32:3967-3973, 2014

10. Press MF, Sauter G, Buyse M, et al: HER2 gene amplification testing by fluorescent in situ hybridization (FISH): Comparison of the ASCO-College of American Pathologists guidelines with FISH scores used for enrollment in breast cancer international research group clinical trials. J Clin Oncol 34:3518-3528, 2016

11. Shah MV, Wiktor AE, Meyer RG, et al: Change in pattern of HER2 fluorescent in situ hybridization (FISH) results in breast cancers submitted for FISH testing: Experience of a reference laboratory using US Food and Drug Administration criteria and American Society of Clinical Oncology and College of American Pathologists guidelines. J Clin Oncol 34: 3502-3510, 2016
12. Press MF, Villalobos I, Santiago $A$, et al: Assessing the new American Society of Clinical Oncology/College of American Pathologists guidelines for HER2 testing by fluorescence in situ hybridization: Experience of an academic consultation practice. Arch Pathol Lab Med 140:1250-1258, 2016

13. Hanna WM, Slodkowska $E$, Lu Fl, et al: Comparative analysis of human epidermal growth factor receptor 2 testing in breast cancer according to 2007 and 2013 American Society of Clinical Oncology/College of American Pathologists guideline recommendations. J Clin Oncol 35:3039-3045, 2017

14. Wolff AC, Hammond ME, Hicks DG, et al: Reply to E.A. Rakha et al. J Clin Oncol 33:1302-1304, 2015

15. Stoss $O C$, Scheel A, Nagelmeier I, et al: Impact of updated HER2 testing guidelines in breast cancerre-evaluation of HERA trial fluorescence in situ hybridization data. Mod Pathol 28:1528-1534, 2015

16. Ballard $M$, Jalikis $F$, Krings $G$, et al: 'Nonclassical' HER2 FISH results in breast cancer: A multiinstitutional study. Mod Pathol 30:227-235, 2017

17. Rakha EA, Pigera M, Shaaban A, et al: National guidelines and level of evidence: Comments on some of the new recommendations in the American Society of Clinical Oncology and the College of American Pathologists human epidermal growth factor receptor 2 guidelines for breast cancer. J Clin Oncol 33:1301-1302, 2015

18. Shojania KG, Sampson M, Ansari MT, et al: How quickly do systematic reviews go out of date? A survival analysis. Ann Intern Med 147:224-233, 2007

19. Lim TH, Lim AS, Thike AA, et al: Implications of the updated 2013 American Society of Clinical Oncology/College of American Pathologists guideline recommendations on human epidermal growth factor receptor 2 gene testing using immunohistochemistry and fluorescence in situ hybridization for breast cancer. Arch Pathol Lab Med 140:140-147, 2016

20. Bethune GC, Veldhuijzen van Zanten $D$, Maclntosh RF, et al: Impact of the 2013 American Society of Clinical Oncology/College of American Pathologists guideline recommendations for human epidermal growth factor receptor 2 (HER2) testing of invasive breast carcinoma: A focus on tumours assessed as 'equivocal' for HER2 gene amplification by fluorescence in-situ hybridization. Histopathology 67:880-887, 2015

21. Solomon JP, Dell'Aquila $M$, Fadare O, et al: Her2/ neu status determination in breast cancer: A single institutional experience using a dual-testing approach with immunohistochemistry and fluorescence in situ hybridization. Am J Clin Pathol 147:432-437, 2017

22. Vingiani $A$, Maisonneuve $P$, Dell'orto $P$, et al: The clinical relevance of micropapillary carcinoma of the breast: A case-control study. Histopathology 63: 217-224, 2013

23. Dako: HercepTest Interpretation Manual: Breast Cancer, 2014 https://www.agilent.com/cs/library/ usermanuals/public/28630_herceptest_interpretation_ manual-breast_ihc_row.pdf

24. Arnedos $M$, Nerurkar $A$, Osin $P$, et al: Discordance between core needle biopsy (CNB) and excisional biopsy (EB) for estrogen receptor (ER), progesterone receptor (PgR) and HER2 status in early breast cancer (EBC). Ann Oncol 20:1948-1952, 2009

25. Hanna WM, Rüschoff J, Bilous M, et al: HER2 in situ hybridization in breast cancer: Clinical implications of polysomy 17 and genetic heterogeneity. Mod Pathol 27:4-18, 2014

26. Tse $\mathrm{CH}$, Hwang HC, Goldstein LC, et al: Determining true HER2 gene status in breast cancers with polysomy by using alternative chromosome 17 reference genes: Implications for anti-HER2 targeted therapy. J Clin Oncol 29:4168-4174, 2011

27. Troxell ML, Bangs $C D$, Lawce $H J$, et al: Evaluation of Her-2/neu status in carcinomas with amplified chromosome 17 centromere locus. Am J Clin Pathol 126:709-716, 2006

28. Moelans $C B$, de Weger $R A$, van Diest PJ: Absence of chromosome 17 polysomy in breast cancer: Analysis by CEP17 chromogenic in situ hybridization and multiplex ligation-dependent probe amplification. Breast Cancer Res Treat 120:1-7, 2010

29. Marchiò $C$, Lambros MB, Gugliotta $P$, et al: Does chromosome 17 centromere copy number predict polysomy in breast cancer? A fluorescence in situ hybridization and microarray-based $\mathrm{CGH}$ analysis. J Pathol 219:16-24, 2009

30. Yeh IT, Martin MA, Robetorye RS, et al: Clinical validation of an array CGH test for HER2 status in breast cancer reveals that polysomy 17 is a rare event. Mod Pathol 22:1169-1175, 2009

31. Vranic $S$, Teruya $B$, Repertinger $S$, et al: Assessment of HER2 gene status in breast carcinomas with polysomy of chromosome 17. Cancer 117:4853, 2011

32. Bianchi S, Caini S, Paglierani M, et al: Accuracy and reproducibility of HER2 status in breast cancer using immunohistochemistry: A quality control study in Tuscany evaluating the impact of updated 2013 ASCO/CAP recommendations. Pathol Oncol Res 21: 477-485, 2015

33. Sneige N, Hess KR, Multani AS, et al: Prognostic significance of equivocal human epidermal growth factor receptor 2 results and clinical utility of alternative chromosome 17 genes in patients with invasive breast cancer: A cohort study. Cancer 123:1115-1123, 2017

34. Prendeville $S$, Feeley L, Bennett MW, et al: Reflex repeat HER2 testing of grade 3 breast carcinoma at excision using immunohistochemistry and in situ analysis: Frequency of HER2 discordance and utility of core needle biopsy parameters to refine case selection. Am J Clin Pathol 145:75-80, 2016

35. Zhang X, Bleiweiss I, Jaffer S, et al: The impact of 2013 updated ASCO/CAP HER2 guidelines on the diagnosis and management of invasive breast cancer: A single-center study of 1739 cases. Clin Breast Cancer 17:486-492, 2017

36. Long $T H$, Lawce $H$, Durum $C$, et al: The new equivocal: Changes to HER2 FISH results when applying the 2013 ASCO/CAP guidelines. Am J Clin Pathol 144:253-262, 2015

37. Varga Z, Noske A: Impact of modified 2013 ASCO/CAP guidelines on HER2 testing in breast cancer. One year experience. PLoS One 10: e0140652, 2015

38. Xu Y, Bai QM, Yang F, et al: Impact of 2013 American Society of Clinical Oncology/College of American Pathologist guidelines on borderline immunostaining results for HER2: A retrospective study on HER2 FISH results in 1780 cases of invasive breast cancers [in Chinese]. Zhonghua Bing Li Xue Za Zhi 45:545-549, 2016

39. Tchrakian N, Flanagan L, Harford J, et al: New ASCO/CAP guideline recommendations for HER2 testing increase the proportion of reflex in situ hybridization tests and of HER2 positive breast cancers. Virchows Arch 468:207-211, 2016

40. Singh K, Tantravahi U, Lomme MM, et al: Updated 2013 College of American Pathologists/ American Society of Clinical Oncology (CAP/ASCO) guideline recommendations for human epidermal growth factor receptor 2 (HER2) fluorescent in situ hybridization (FISH) testing increase HER2 positive 
and HER2 equivocal breast cancer cases; retrospective study of HER2 FISH results of 836 invasive breast cancers. Breast Cancer Res Treat 157:405-411, 2016

41. Fan YS, Casas CE, Peng J, et al: HER2 FISH classification of equivocal HER2 IHC breast cancers with use of the 2013 ASCO/CAP practice guideline. Breast Cancer Res Treat 155:457-462, 2016

42. Muller KE, Marotti JD, Memoli VA, et al: Impact of the 2013 ASCO/CAP HER2 guideline updates at an academic medical center that performs primary HER2 FISH testing: Increase in equivocal results and utility of reflex immunohistochemistry. Am J Clin Pathol 144:247-252, 2015

43. Krop I, Ismaila N, Andre F, et al: Use of biomarkers to guide decisions on adjuvant systemic therapy for women with early-stage invasive breast cancer: American Society of Clinical Oncology clinical practice guideline focused update. J Clin Oncol 35: 2838-2847, 2017

44. Denduluri $N$, Somerfield MR, Eisen $A$, et al: Selection of optimal adjuvant chemotherapy regimens for human epidermal growth factor receptor 2 (HER2)-negative and adjuvant targeted therapy for HER2-positive breast cancers: An American Society of Clinical Oncology guideline adaptation of the Cancer Care Ontario Clinical Practice guideline. J Clin Oncol 34:2416-2427, 2016

45. Henry NL, Somerfield MR, Abramson VG, et al: Role of patient and disease factors in adjuvant systemic therapy decision making for early-stage, operable breast cancer: American Society of Clinical Oncology endorsement of Cancer Care Ontario guideline recommendations. J Clin Oncol 34: 2303-2311, 2016

46. Van Poznak C, Somerfield MR, Bast RC, et al: Use of biomarkers to guide decisions on systemic therapy for women with metastatic breast cancer: American Society of Clinical Oncology clinical practice guideline. J Clin Oncol 33:2695-2704, 2015

47. Partridge $A H$, Rumble $R B$, Carey $L A$, et al: Chemotherapy and targeted therapy for women with human epidermal growth factor receptor 2-negative (or unknown) advanced breast cancer: American Society of Clinical Oncology clinical practice guideline. J Clin Oncol 32:3307-3329, 2014

48. Giordano SH, Temin S, Kirshner JJ, et al: Systemic therapy for patients with advanced human epidermal growth factor receptor 2-positive breast cancer: American Society of Clinical Oncology clinical practice guideline. J Clin Oncol 32:2078-2099, 2014

49. Ramakrishna N, Temin S, Chandarlapaty S, et al: Recommendations on disease management for patients with advanced human epidermal growth factor receptor 2-positive breast cancer and brain metastases: American Society of Clinical Oncology clinical practice guideline. J Clin Oncol 32:2100-2108, 2014

50. Hammond ME, Hayes DF, Dowsett $M$, et al: American Society of Clinical Oncology/College of American Pathologists guideline recommendations for immunohistochemical testing of estrogen and progesterone receptors in breast cancer. J Clin Oncol 28:2784-2795, 2010

\section{Affiliations}

Antonio C. Wolff, Johns Hopkins Sidney Kimmel Comprehensive Cancer Center, Baltimore; Lisa M. McShane, National Cancer Institute, Bethesda, MD; M. Elizabeth Hale Hammond, Intermountain Healthcare and University of Utah School of Medicine, Salt Lake City, UT; Kimberly H. Allison, Stanford University School of Medicine, Stanford; Patrick Fitzgibbons, St Jude Medical Center, Fullerton; Michael F. Press, University of Southern California, Los Angeles, CA; Brittany E. Harvey and Pamela B. Mangu, American Society of Clinical Oncology, Alexandria, VA; John M.S. Bartlett, Ontario Institute for Cancer Research; Wedad Hanna, Sunnybrook Health Sciences Centre and Women's College Hospital, Toronto, Ontario, Canada; Michael Bilous, Western Sydney University and Australian Clinical Laboratories, Sydney, New South Wales, Australia; Ian O. Ellis, The University of Nottingham, Nottingham; Mitchell Dowsett, The Royal Marsden NHS Foundation Trust, London, United Kingdom; Robert B. Jenkins, Mayo Clinic, Rochester, MN; Patricia A. Spears, Cancer Information and Support Network, Raleigh, NC; Gail H. Vance, Indiana University School of Medicine, Indianapolis, IN; and Giuseppe Viale, University of Milan and Istituto Europeo di Oncologia, Milan, Italy.

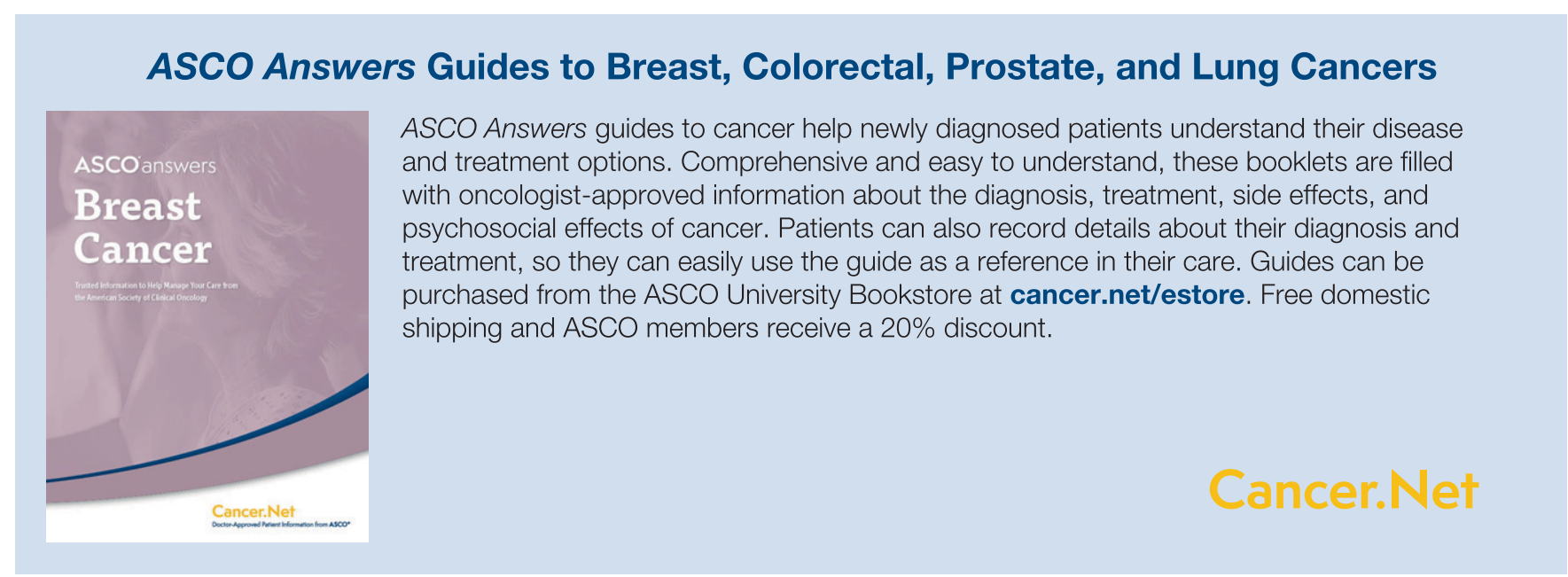




\section{AUTHORS' DISCLOSURES OF POTENTIAL CONFLICTS OF INTEREST}

Human Epidermal Growth Factor Receptor 2 Testing in Breast Cancer: American Society of Clinical Oncology/College of American Pathologists Clinical Practice Guideline Focused Update

The following represents disclosure information provided by authors of this manuscript. All relationships are considered compensated. Relationships are self-held unless noted. I = Immediate Family Member, Inst = My Institution. Relationships may not relate to the subject matter of this manuscript. For more information about ASCO's conflict of interest policy, please refer to www.asco.org/rwc or ascopubs.org/jco/site/ifc.

\section{Antonio C. Wolff}

Research Funding: Pfizer (Inst)

Patents, Royalties, Other Intellectual Property: Antonio C. Wolff has been named as inventor on one or more issued patents or pending patent applications relating to methylation in breast cancer and has assigned his rights to Johns Hopkins University, and participates in a royalty sharing agreement with Johns Hopkins University.

\section{Elizabeth Hale Hammond}

No relationship to disclose

\section{Kimberly H. Allison}

Expert Testimony: Kaiser Permanente

\section{Brittany E. Harvey}

No relationship to disclose

\section{Pamela B. Mangu}

No relationship to disclose

\section{John M.S. Bartlett}

Honoraria: Oncology Education

Consulting or Advisory Role: Insight Genetics, BioNTech AG, Due North, bioTheranostics

Research Funding: NanoString Technologies, BioNTech, Agendia NV, Thermo Fisher Scientific

Patents, Royalties, Other Intellectual Property: Five pending patents: (1) January 2017: Methods and Devices for Predicting Anthracycline Treatment Efficacy; US application, 15/325472; EP application, 3169815A1; Canada application, not yet assigned. (2) January 2017: Systems, Devices and Methods for Constructing and Using a Biomarker; US application 15328108; EP 3172362A4; Canada application, not yet assigned. (3) October 2016: Histone gene module predicts anthracycline benefit, PCT/CA2016/0002474. (4) December 2016: 95-Gene Signature of Residual Risk Following Endocrine Treatment, PCT/CA2016/0003045. (5) December 2016: Immune Gene Signature Predicts Anthracycline Benefit, PCT/CA2016/000305 (Inst)

\section{Michael Bilous}

Honoraria: Hoffmann-La Roche

Consulting or Advisory Role: Hoffmann-La Roche

Travel, Accommodations, Expenses: Hoffmann-La Roche
Ian O. Ellis

Employment: Source BioScience PLC

Stock or Other Ownership: Source BioScience PLC

Patrick Fitzgibbons

Stock or Other Ownership: Johnson \& Johnson, Pfizer, Medtronic, Merck

\section{Wedad Hanna}

No relationship to disclose

Robert B. Jenkins

Patents, Royalties, Other Intellectual Property: Royalties from Abbott Molecular; royalties from Genome Diagnostics

Michael F. Press

Honoraria: Biocartis, Halozyme Therapeutics, Puma Biotechnology, Cepheid, Ventana Medical Systems, Eli Lilly, Karyopharm Therapeutics, ADC Therapeutics, Scripps Health

Consulting or Advisory Role: Biocartis, Halozyme Therapeutics, Puma Biotechnology, Cepheid, Ventana Medical Systems, ADC Therapeutics, Eli Lilly, Karyopharm Therapeutics, Brogent International

Patricia A. Spears

Consulting or Advisory Role: Pfizer

Travel, Accommodations, Expenses: Roche/Genentech

Gail H. Vance

Expert Testimony: Washington Mutual Insurance

\section{Giuseppe Viale}

Honoraria: MSD

Consulting or Advisory Role: Dako, Roche/Genentech, AstraZeneca, Bristol-Myers Squibb, Astellas Pharma

Speakers' Bureau: Pfizer

Travel, Accommodations, Expenses: Roche, Celgene

Lisa M. McShane

No relationship to disclose

Mitchell Dowsett

Honoraria: Novartis, Pfizer, Myriad Genetics

Consulting or Advisory Role: Radius Health

Research Funding: Pfizer (Inst), Radius Health (Inst)

Other Relationship: Institute of Cancer Research 


\section{Acknowledgment}

The Expert Panel thanks Gary Lyman, Cynthia Anderson, the Clinical Practice Guidelines Committee, and the CAP Advisory and Independent Review Panels for their thoughtful reviews and insightful comments on this guideline. The Expert Panel also wishes to thank Neil Goldstein, Allen Gown, Erin Grimm, Christine Houston, Loralee McMahon, Dylan Miller, Bill Wyatt, and Hadi Yaziji for sharing their routine clinical experience with HER2 testing in breast cancer through the research survey and open session of the meeting, and those who participated in the online open comment period for providing feedback and suggestions for improving the guideline recommendations.

\section{Appendix}

Table A1. Focused Update of ASCO/College of American Pathologists Breast Cancer Clinical Practice Guideline on HER2 Testing Expert Panel Membership Expert Panel Member Institution

Antonio C. Wolff (co-chair)*

M. Elizabeth Hale Hammond (co-chair)*

Kimberly H. Allison*

John M.S. Bartlett

Michael Bilous

Ian O. Ellis

Patrick Fitzgibbons

Wedad Hanna

Robert B. Jenkins

Michael F. Press

Patricia A. Spears (patient representative)

Gail H. Vance

Giuseppe Viale

Lisa M. McShane*

Mitchell Dowsett*

Brittany E. Harvey

Pamela B. Mangu

Johns Hopkins Sidney Kimmel Comprehensive Cancer Center

Intermountain Healthcare and University of Utah School of Medicine

Stanford University School of Medicine

Ontario Institute for Cancer Research

Western Sydney University and Australian Clinical Laboratories

The University of Nottingham

St Jude Medical Center

Sunnybrook Health Sciences Centre and Women's College Hospital Mayo Clinic

University of Southern California

Cancer Information and Support Network

Indiana University School of Medicine

University of Milan and Istituto Europeo di Oncologia

National Cancer Institute

The Royal Marsden NHS Foundation Trust

American Society of Clinical Oncology

American Society of Clinical Oncology

Abbreviation: HER2, human epidermal growth factor receptor 2 .

* Steering Committee member. 